\title{
A Comprehensive Study on Intrusion and Extrusion Phenomena
}

\author{
Md. Abdul Hamid ${ }^{1}$ \\ Department of Information Technology \\ King AbdulAziz University \\ Jeddah-21589 Kingdom of Saudi Arabia
}

\author{
Muhammad Mostafa Monowar ${ }^{4}$ \\ Department of Information Technology \\ King AbdulAziz University \\ Jeddah-21589 Kingdom of Saudi Arabia
}

\author{
Marjia Akter ${ }^{2}$ \\ Department of CSE \\ University of Asia Pacific \\ Dhaka, Bangladesh
}

\author{
M. F. Mridha ${ }^{3}$ \\ Department of CSE \\ Bangladesh University of Business \& \\ Technology, Dhaka, Bangladesh
}

\begin{abstract}
This paper presents a comprehensive survey on intrusion and extrusion phenomena and their existing detection and prevention techniques. Intrusion and extrusion events, breach of security system, hamper the protection of the devices or systems. Needless to say that security threats are flourishing with new level of complexity making difficulty in recognizing them. Therefore, security is the remarkable issue at the core of developing a boundless, constant and reliable web. In this paper, our purpose is to unveil and categorize all possible intrusion and extrusion events, bring out issues related to events and explore solutions associated with them. Nevertheless, we suggest further recommendations to improve the security in these issues. We strongly believe that this survey may help understanding intrusion and extrusion phenomena, and pave the way for a better design to protect against security threats.
\end{abstract}

Keywords-Intrusion; extrusion; intrusion detection; security and survey

\section{INTRODUCTION}

No doubt, computing technology has changed the lifestyle of people drastically. All of these are happening through connecting devices, we call it networks. As devices are getting smarter and knowledgeable, people became much more dependent towards these devices. Things that come with comfort and contentment also brings issues and worries with it.

As networks are assisting individuals to communicate through the connecting devices, threats and breaches are getting more prominent. Computer security is the protection of electronic data and information against inner and outer, malevolent and vulnerability threats [1]. It renders protection as well as prevention from attacks and keeps the information secure. However, due to growth of the new technologies along with sophisticate devices, types and nature of the attacks are also changing [2].

All probable occurrences, contraventions, or approaching threats that violate system security are known as intrusion and extrusion events. More precisely, if an insider or outsider potentially intrudes the local system with his own remote system, it is known as intrusion event. Extrusion, known as an attack event, that generates from the local host system to take control over the system. It is usually done by the insider who

\author{
Madini O. Alassafi ${ }^{5}$ \\ Department of Information Technology \\ King AbdulAziz University \\ Jeddah-21589 Kingdom of Saudi Arabia
}

is authorized to use any devices of the organization. To shield devices and networks against intrusion or extrusion events, security must be enough savvy and intelligent [3]. The concept of network security was first initiated in the late 1980s and since then experts have been exhorted to the unpredictable risk of numerous unsecured interconnected devices to the internet [4]. Now a days, numerous attacks events relate to intrusion and extrusion are continuously increasing concerns, devices like computer, refrigerators and even TVs are being used to dispatch malicious things to hackers. Hackers usually do not attack the devices themselves, but instead use other malicious devices to break into [5].

Some remarkable attack events related to intrusion and extrusion that affected the world most are RFIT botnet (December, 2018), ThinkPHP exploitation (11 December, 2018), D-link router exploitation, Shaolin botnet (exploitation of NETGEAR vulnerability, January, 2019), Mirai botnet [6]|7], the botnet barrage, Notpetya ransomware attack (June, 2017), etc. Most of these attacks are not discussed and also not prevented even though systems have enough security. So, it is hard to accept that even after 28-years, system does not have enough security to detect or prevent such events. Without these exception, devices and systems also face some regular intrusion and extrusion attacks, such as Address resolution protocol attack, Internet Control Message Protocol (ICMP) attack, Fraggle attack, ICMP tunneling attack, Internet Protocol (IP) fragment attack, Malformed packet, Outbound raw attack, Ping-of-death attack, Distributed denial of services, Phishing, Supply chain attack, Router attack etc, to name a few.

Although the conventional solutions exist on the aforementioned attacks, still the occurrence of the mentioned remarkable events indicate that no systems are fully protected. We have explored a large number of surveys on attacks. Some surveys [8][9][10][11] discussed about the attacks in different layers - Some [12][13][14] have only discussed about DDoS attacks. Some [15][16][17] surveys mainly focused on intrusion detection and prevention systems. As network is expanding its region, more intrusion and extrusion events are occurring which are never discussed before.

This article incorporates up-to-date taxonomy, as well 
as descriptions of important scientific work in the field of incursion and extrusion. It offers an overview of the current intrusion and extrusion detection system in an organized and thorough fashion so that interested academics may rapidly learn about essential areas of anomaly detection. The intricacy and implications of the various approaches and their assessment procedures will be explored.

There have been no papers that thoroughly cover infiltration and extrusion detection, outcomes, and various types of attacks. Furthermore, the advancement of intrusion-detection systems has resulted in the proposal of numerous distinct systems in the interim. This document provides up-to-date information on the subject.

We have presented a comprehensive and in depth study on intrusion and extrusion events. Mostly, extrusion attacks [18] and their detection systems [19] are not covered in existing surveys. For better understanding, we have discussed about attacks' real-life examples, constructive definitions, attacks' consequences, their complexities, limitations and merits, method comparison and efficiency, etc.

As time passes, a scenario with a relatively novel phenomena emerges, and network defenses are inadequate. Because of the ubiquity of computer networks and our ever-increasing reliance on them, becoming aware of the threat might have disastrous repercussions. The density of study on this topic is continually increasing, and more scholars are becoming involved in this field of work on a daily basis. The potential of a new wave of cyber or network assaults is not just a possibility to be considered; it is a known truth that can occur at any time. We think that study should not be restricted to the concerns raised in this work.

Nevertheless, most of these events have never been categorized for understanding of the problems. In our paper, we categorize the attacks on the basis of intrusion and extrusion and we provide a comprehensive discussion on those events for better understanding. We further relate those events in terms of TCP/IP layers. All these motivated us in writing this article. We firmly believe that our effort might convey indelible influence to the research community towards next level of perfection.

The rest of the of paper is organized as follows. Section 2 outlines the taxonomy of intrusion and extrusion events. The intrusion events are described in details in Section 3. Section 4 continues with the detailed description on extrusion events. We present a big picture in tabular form summarizing all the intrusion and extrusion events in Section 5. Finally, We present open challenges and future research Issues in Section 6 and at end, we conclude our research in Section 7.

\section{TAXONOMY OF INTRUSION AND EXTRUSION}

This paper categorizes different attacks into intrusion and extrusion events. Nevertheless, each of the attack is associated with any of the layers in TCP/IP protocol suite. Hence, our main classification also exhibits the corresponding layer where the attack occurs as demonstrated in Fig. 1. We have enlisted 14 intrusion and 10 extrusion events knowing that this list will grow in course of time. AS far as our knowledge perceives, this is the first attempt that accumulates all the intrusion and extrusion events, along with their comparative analyses.

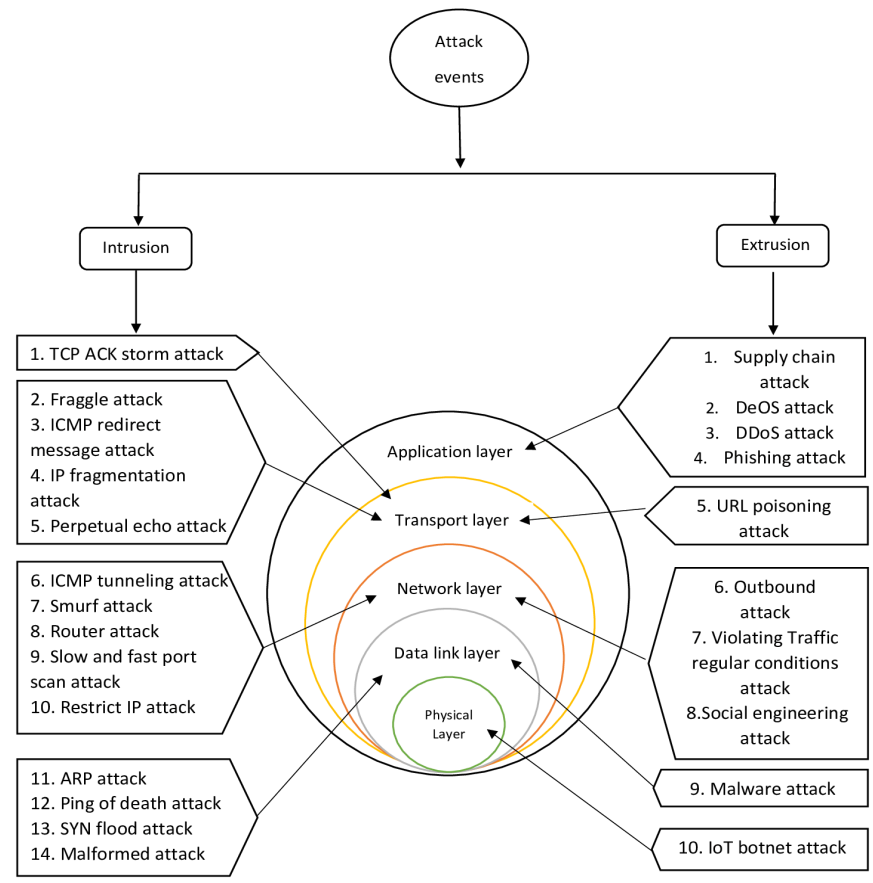

Fig. 1. An Overall Taxonomy of Intrusion and Extrusion Events.

\section{INTRUSION EVENTS}

This body of our work digs out the intrusion events manifesting their definitions, explaining how they occur and presenting the possible solutions for them along with figures wherever applicable. When a trusted insider violates the regular use of the system, then an intrusion event occur. The most common intruders may be the hackers, company's employees, criminal enterprises etc. Any attack that roots from a remote system to a local system is considered to be intrusion. Suppose, an attacker disguises himself as a legitimate host and sends request (i.e. malware, malformed packets, emails, etc.) to the targeted PC. If an authorized user accepts the request, the malware or malformed packets might attack or freeze his PC or this request might lead him to a proxy fake website and force him to fill the personal information. Thus, the information will be revealed to the attacker. This process is known as intrusion event. Fig. 2 illustrates a generalized model of how intrusion event occurs.

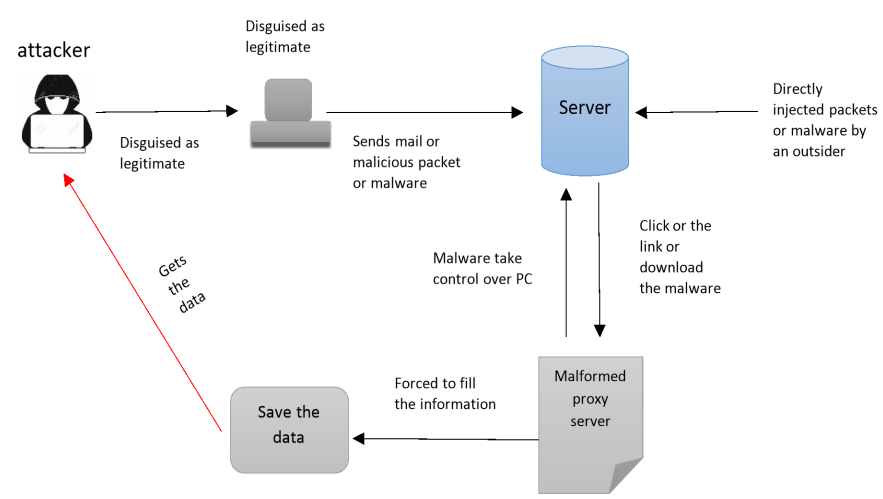

Fig. 2. A Generalized Model Depicting the Occurrence of an Intrusion Event. 


\section{A. TCP-ACK Storm Attack}

This particular attack occurs over TLS/SSL connections along with TCP connections that remain unprotected. However, system having IPsec or link-layer encrypted connections is protective against this attack [20].

It is launched by a man in the middle attacker who only eavesdrops when needed and creates malicious packets. Theoretically, this attack[21] might spread in a limitless manner . The worst case can be N-packets of ACK-storm DoS attack may consume the overall bandwidth of a network. When a receiver receives an unacceptable packet from the attacker, the host acknowledges the packet and sends the expected sequence number to the attacker by using its own sequence number. In most cases, an attacker receives a packet with receiver's sequence number larger than the one sent by a receiving client with the standard TCP connection. Even though, this packet is unacceptable, it generates an acknowledgment packet. This generated packet eventually generates other acknowledgment packets causing unlimited loops for each data packet. Whenever the ACK packet [22] is lost, it will not be retransmitted since it contains no meaningful data. ACK storm is less if the network drops more packets.

The Mitnick case (1994): A disguised attacker verily hacked the computers in the San Diego Supercomputer Center. This was happened to be the most secure computer system in US [23]. The financial services industry also experienced same type of attack. In March 2019, the attack was so sophisticated which was not previously seen before. Though it has an easy fix by tuning TCP or using a packet-filtering firewall system.

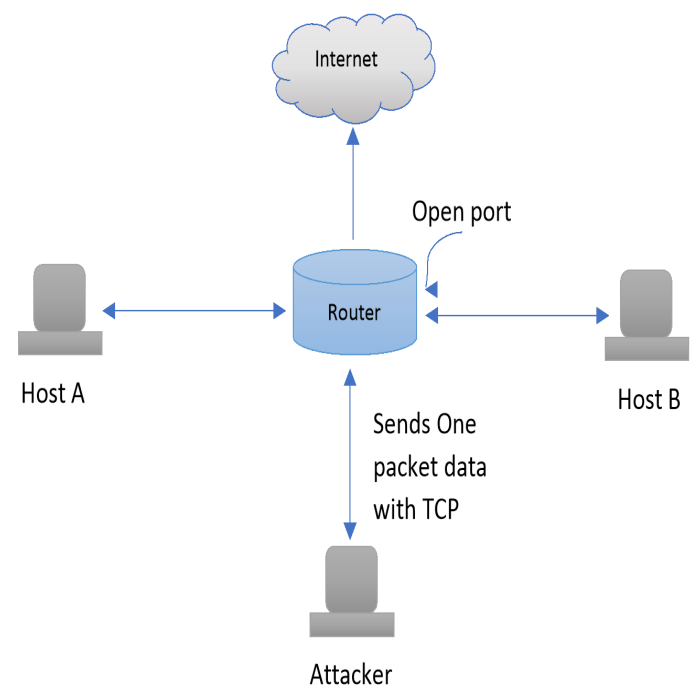

Fig. 3. TCP-ACK Storm: Attacker Changes One Network Packet with Malicious Packet.

Fig. 3 depicts the procedure of TCP-ACK storm with one packet that consists of three processes:

1) Attacker picks up a packet from connected network among host $\mathrm{A}$ and host $\mathrm{B}$ as there is an open port exist in the router.

2) Then, attacker generates one packet which will address to host A and sends with host A's address to host B. Packet must have at least one byte of data. Packet must be inside the TCP connection.

3) Finally, hacker manages to send packets form Host A to Host B maintaining the time frame. As the attackers gets reply, it will continue in a loop of back and forth of packets.

The basic one packet TCP-ACK storm attack [24] can be further amplified to the Two-packets Ack-Storm attack, exhausting bandwidth and lengthening the session duration. This attack causes disruption of the regular web activities by sending huge traffic.

Some existing solutions related to this attack are shown in Table I.

\section{B. Fraggle Attack}

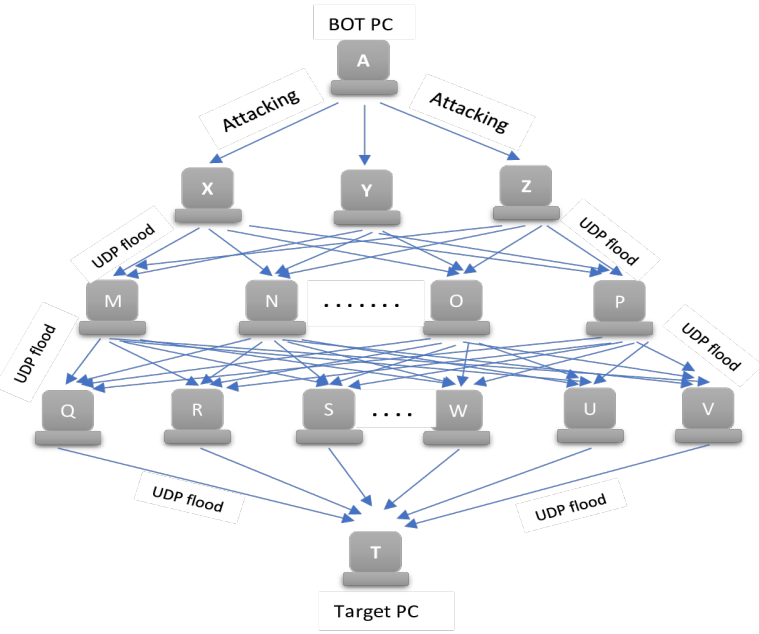

Fig. 4. An Example of Fraggle Attack.

Fig. 4 attacker is attacking the computers using BOT PC A to generate UDP flood to PC X, Y and Z. This UDP flood is then propagated to the nodes downward. Note that, port 7 is open for all computers and it supports character generation system. Eventually, the traffic will overwhelm the target PC T and block its normal functioning, resulting in fraggle attack.

The Fraggle attack is a type of amplification attack where UDP packets are dispatched to ports 7 and 19 depending on which one is open. Also, character generation service may run which is eligible for character generation. This intrusion may cause havoc to the system with the help of the insiders as they unintentionally help the hackers to flood UDP packets. As this attack is not new, all operating systems are protected from such attack. Therefore, no new such attacks [28] have been found nowadays, although in the late 90s, the attack was very acute.

A successful attempt of Fraggle attack may hang any system servers for an indefinite period of time (e.g., hours, days or even months). To Identify Fraggle attack, three types of techniques are introduced: traffic degree monitoring, source IP address monitoring, and packet attributes analysis. When the attack is detected, some countermeasures might be taken such as filtration [29], congestion control [30], Submissive trace back [31], Reproduction [32], etc. 
TABLE I. STATE-OF-THE-ART SOLUTIONS OF TCP-ACK STORM

\begin{tabular}{|c|c|c|c|c|c|c|c|c|}
\hline Reference & $\begin{array}{l}\text { Proposed } \\
\text { Method/ } \\
\text { Model }\end{array}$ & Detection & Prevention & Limitations & Merit & Efficiency & $\begin{array}{l}\text { Code } \\
\text { modifi- } \\
\text { cation }\end{array}$ & $\begin{array}{l}\text { Applied } \\
\text { to all } \\
\text { platform }\end{array}$ \\
\hline $\begin{array}{l}\text { Raz et al } \\
2011|25|\end{array}$ & $\begin{array}{l}\text { Modifying } \\
\text { the TCP }\end{array}$ & $x$ & $\sqrt{ }$ & $\begin{array}{l}\text { Hassle-some } \\
\text { for the network } \\
\text { architecture. }\end{array}$ & $\begin{array}{l}\text { Generated everlasting } \\
\text { TCP amplification }\end{array}$ & $\begin{array}{l}\text { only } 1 \% \\
\text { packet loss }\end{array}$ & Yes & Yes \\
\hline $\begin{array}{l}\text { Neminath } \\
\text { et al } 2018 \\
{[22]}\end{array}$ & $\begin{array}{l}\text { State } \\
\text { transition } \\
\text { model }\end{array}$ & $\checkmark$ & $x$ & $\begin{array}{l}\text { Snatches TCP's } \\
\text { capability to re- } \\
\text { synchronising } \\
\text { the sequence } \\
\text { numbers }\end{array}$ & $\begin{array}{l}\text { Real experiment of at- } \\
\text { tack and detection in } \\
\text { test bed setup }\end{array}$ & $\begin{array}{l}\text { Close } \\
100 \%\end{array}$ & Yes & Yes \\
\hline $\begin{array}{l}\text { Duc et al } \\
2019 \text { [26] }\end{array}$ & $\begin{array}{l}\text { Hypervisor } \\
\text { at close } \\
\text { state }\end{array}$ & $\checkmark$ & $x$ & $\begin{array}{l}\text { Analyzed } \\
\text { TCP ACK } \\
\text { Storm DoS } \\
\text { attack against } \\
\text { virtual network } \\
\text { systems }\end{array}$ & $\begin{array}{l}\text { Defining the packet } \\
\text { size every-time is hard } \\
\text { for the system }\end{array}$ & $\begin{array}{l}\text { Takes } \\
60 \mathrm{sec} \\
\text { detect }\end{array}$ & No & No \\
\hline
\end{tabular}

\section{An ICMP Redirect Message Attack}

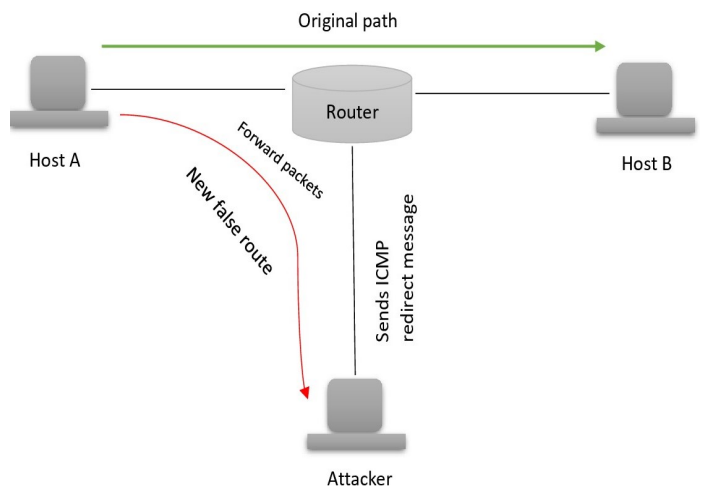

Fig. 5. ICMP Redirect Message Attack: Attackers Manipulating ICMP Messages between Server and Client's PC.

ICMP redirect message sends out of bound message that passes the information to a host regarding the existence of more optimal routes through the server network. But this system is effectively misused by the attacker to redirect the traffic or information to his own system. In this attack, the hacker poisons the router by sending ICMP redirect message to the targeted host, so that all traffic uses optimal way for the destination. These attacks mostly happen on the port or network layer. These attacks can also cause problems if there exists firewall and non-deterministic traffic [33]. Zimperium Mobile Security Labs have researched last year attack named "DoubleDirect" which can be generated through ICMP redirect massage attack. It enables the attacker to redirect target's traffic [34] to attacker's PC. Once the process is done, attacker may steal or inject payload to the victim's PC. Machine learning approach generates the best detection rate till now.

In Fig. 5 host $\mathrm{A}$ is the source and host $\mathrm{B}$ is the destination. The files are supposed to transfer from source to destination through router. But the attacker redirects the messages by manipulating the router. Hence, the files finds the new path and goes to the attacker's PC considering it as the destination. In what follows, the Table [I] enlists some existing solutions to this attacks.

\section{Internet Protocol (IP) Fragmentation Attack}

IP fragmentation attack exploits the IP fragmentation mechanism as an attack vector [40] [41].

Black nurse attack is one of the most common organizational names of IP fragmentation attack. Basically, it is based on sending crafted IP fragments in order to eliminate firewall services [42].

This process may occur in two ways as described in the following:

1) UDP and ICMP fragmentation attacks: This attack [43] exploits the transmission of malicious UDP or ICMP packets exceeding the maximum transmission unit. The inability of reassembling these packets causes high resource consumption resulting in the victim server issues.

2) TCP fragmentation attacks: This attack, also regarded Teardrop attack, inhibits reassembly procedure of the TCP/IP for the fragmented data packets resulting in data packets overlap. Consequently, the server gets swamped [44].

Improving packet loss and 95\% accuracy rate makes sparsely tagged fragmentation marking a best solution for this attack. Table III presents existing solutions related to this attack.

\section{E. Perpetual Echo Attack}

Perpetual echo attack [51], a fraudulent activity, takes place at port 7. Source port and the destination port perpetually echo each other when the connection is established. UDP requests are sent to a malicious IP address for all victims to get back their responses. The malicious source address is not the 
(IJACSA) International Journal of Advanced Computer Science and Applications,

TABLE II. State-OF-THE-ARt Solutions of An ICMP Redirect Message AtTaCK

\begin{tabular}{|c|c|c|c|c|c|c|c|c|}
\hline Reference & $\begin{array}{l}\text { Proposed } \\
\text { Method/ } \\
\text { Model }\end{array}$ & Detection & Prevention & Limitations & Merit & Efficiency & $\begin{array}{l}\text { Code } \\
\text { modifi- } \\
\text { cation }\end{array}$ & $\begin{array}{l}\text { Applied } \\
\text { to all } \\
\text { platform }\end{array}$ \\
\hline $\begin{array}{lr}\text { Prerna } & \text { et } \\
\text { al. } & 2015 \\
35 & \end{array}$ & $\begin{array}{l}\text { Centralized } \\
\text { system }\end{array}$ & $\bar{x}$ & $\sqrt{ }$ & $\begin{array}{l}\text { If Central server is } \\
\text { unable to find cor- } \\
\text { rect match, it needs } \\
\text { to send broadcast } \\
\text { request. Time com- } \\
\text { plexity increases }\end{array}$ & $\begin{array}{lr}\text { Analyze } & \text { ICMP } \\
\text { and } & \text { Voting } \\
\text { with } & \text { Backward } \\
\text { Compatibility, Less } \\
\text { Cost, Minimal } \\
\text { Traffic and Easily } \\
\text { deployed }\end{array}$ & $\begin{array}{l}\text { comple- } \\
\text { xity } \\
\mathrm{O}(\log \mathrm{N})\end{array}$ & Yes & Yes \\
\hline $\begin{array}{l}\text { Jaspreet et } \\
\text { al. } 2017 \\
{[36]}\end{array}$ & $\begin{array}{l}\text { Signature } \\
\text { based } \\
\text { machine } \\
\text { learning } \\
\text { tool }\end{array}$ & $\sqrt{ }$ & $x$ & Low accuracy rate & $\begin{array}{l}\text { Application of ma- } \\
\text { chine learning tools }\end{array}$ & $\begin{array}{l}93 \% \text { accu- } \\
\text { racy }\end{array}$ & No & No \\
\hline $\begin{array}{l}\text { Dalal et al. } \\
2018 \text { [33] }\end{array}$ & $\begin{array}{l}\text { PrECast } \\
\text { proxy } \\
\text { service }\end{array}$ & $x$ & $\sqrt{ }$ & $\begin{array}{l}\text { No solution for } \\
\text { DNS amplification } \\
\text { originated from an } \\
\text { external network } \\
\text { towards a r host } \\
\text { inside a LAN }\end{array}$ & $\begin{array}{lr}\text { Cryto } & \text { free } \\
\text { solution } & \text { without } \\
\text { modification } & \text { of } \\
\text { protocol } & \end{array}$ & $\begin{array}{l}\text { complexity } \\
\text { and conver- } \\
\text { gence time } \\
\text { can take } \\
\text { upto } 200 \\
\text { massages }\end{array}$ & Yes & $\begin{array}{l}\text { Yes but } \\
\text { some } \\
\text { modifi- } \\
\text { cation } \\
\text { re- } \\
\text { quired. }\end{array}$ \\
\hline $\begin{array}{lr}\text { Ahmed et } \\
\text { al. } & 2018 \\
37 & \end{array}$ & $\begin{array}{l}\text { AR-match } \\
\text { technique }\end{array}$ & $x$ & $\sqrt{ }$ & $\begin{array}{l}\text { Weak hash function } \\
\text { algorithm for high- } \\
\text { security purpose }\end{array}$ & $\begin{array}{l}\text { solving High com- } \\
\text { plexity using Ar- } \\
\text { match technique }\end{array}$ & $\begin{array}{l}\text { Not } \\
\text { mentioned }\end{array}$ & Yes & Yes \\
\hline $\begin{array}{l}\text { Viegas } \\
\text { et al. } \\
2019[38]\end{array}$ & BigFlow & $\sqrt{ }$ & $x$ & $\begin{array}{l}\text { Only Worked on } \\
\text { limited bandwidth }\end{array}$ & $\begin{array}{l}\text { Analyze the behav- } \\
\text { ior of several tra- } \\
\text { ditional ML classi- } \\
\text { fiers }\end{array}$ & $\begin{array}{l}\text { Accuracy } \\
\text { approx- } \\
\text { imately } \\
90 \%\end{array}$ & Yes & Yes \\
\hline $\begin{array}{l}\text { Jonas et al. } \\
2019[39\end{array}$ & Open Flow & $x$ & $\sqrt{ }$ & $\begin{array}{l}\text { There is no rate } \\
\text { limiting of the Vir- } \\
\text { tual machine when } \\
\text { sending to much } \\
\text { traffic into the net- } \\
\text { work }\end{array}$ & $\begin{array}{l}\text { improvement of se- } \\
\text { curity of libvirt vir- } \\
\text { tual machines con- } \\
\text { nect via an Open } \\
\text { vSwitch }\end{array}$ & $\begin{array}{l}\text { Not } \\
\text { mentioned }\end{array}$ & No & No \\
\hline
\end{tabular}

attacker's correct address. Hence, the hacker remains disguised and the targeted user becomes the victim of large traffic. This may lead to DoS attacks [52] on the UDP ports. Some UDP applications unconditionally respond to every datagram received. If a datagram is inserted into the network with one of these applications as the destination and another of these applications spoofed as the source, the two applications will respond to each other continually. Each inserted datagram will result in another perpetual echo conversation between them. In the worst case, attacker's attempt is to hide attacks or render them and become untraceable. Ant colony optimization has more efficiency to generate true alarm rate while detecting the attack

In Fig. 6, attacker uses another PC's IP address to remain hidden and sends UDP flood through port 7 of the router to the target $\mathrm{PC}$ to establish connection. If one connection is established, the affected PC will be working as BOT that sends UDP flood to other PC. Table [V] presents existing solutions to this attack.

\section{F. Internet Control Message Protocol (ICMP) Tunneling At- tack}

ICMP tunnel is created where the information flow may not be regulated by security technique. ICMP is used as an attack vector shield of IP-Sec gateway [55]. In the worst case,

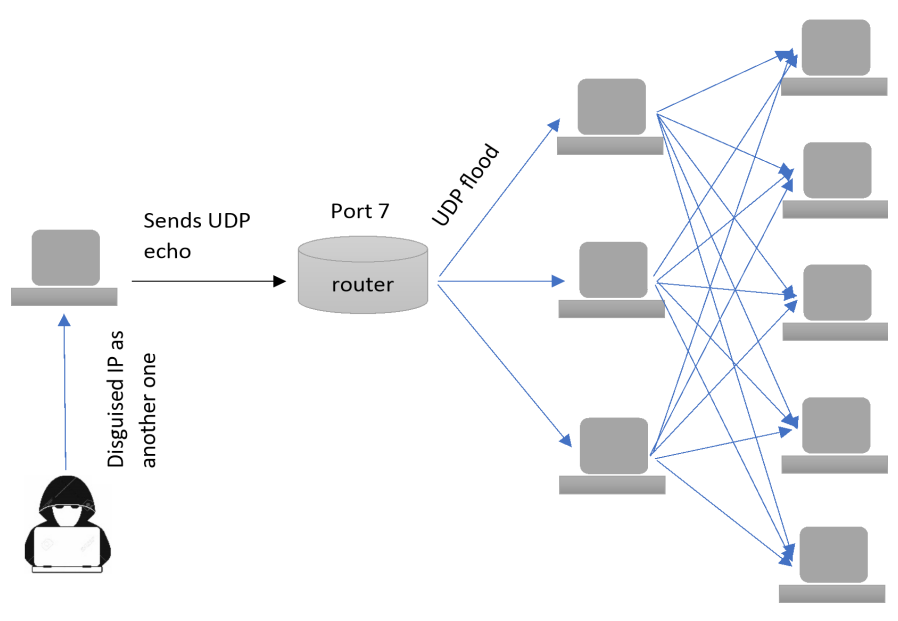

Fig. 6. Echo on user Datagram Protocol (UDP) Ports: Source Port Perpetuals Echo to All Target Ports Modified by Attacker.

attackers are able to disturb the network design architecture by doing malicious activity. An ICMP tunneling attack makes connection between the hosts, and ruins the firewall service in a way that it fails to alarm if any data sent via ICMP. It is a covert connection [56] between hosts using ICMP messages 
(IJACSA) International Journal of Advanced Computer Science and Applications,

TABLE III. State-of-the-Art Solutions of Internet Protocol(IP) Fragmentation Attack

\begin{tabular}{|c|c|c|c|c|c|c|c|c|}
\hline Reference & $\begin{array}{l}\text { Proposed } \\
\text { Method/ } \\
\text { Model }\end{array}$ & Detection & Prevention & Limitations & Merit & Efficiency & $\begin{array}{l}\text { Code } \\
\text { modifi- } \\
\text { cation }\end{array}$ & $\begin{array}{l}\text { Applied } \\
\text { to all } \\
\text { platform }\end{array}$ \\
\hline $\begin{array}{l}\text { Bernstein } \\
\text { et al } 2012 \\
\text { [45] }\end{array}$ & $\begin{array}{l}\text { Edwards- } \\
\text { curve } \\
\text { Digital } \\
\text { Signature } \\
\text { Algorithm }\end{array}$ & $x$ & $\sqrt{ }$ & $\begin{array}{l}\text { It is not a bench- } \\
\text { mark framework }\end{array}$ & $\begin{array}{lr}\text { Strong } & \text { defenses } \\
\text { against } & \text { software } \\
\text { side-channel attack }\end{array}$ & $\begin{array}{l}\text { Drastically } \\
\text { reducing } \\
\text { the number } \\
\text { of branches }\end{array}$ & Yes & No \\
\hline $\begin{array}{l}\text { Mahmud } \\
\text { et al. } \\
\text { 2018 } 47 \text {. }\end{array}$ & $\begin{array}{l}\text { SecuPAN } \\
\text { proposed } \\
\text { tool } \\
\end{array}$ & $\sqrt{ }$ & $\sqrt{ }$ & Mitigates the attack & $\begin{array}{l}\text { verify authenticity } \\
\text { and integrity }\end{array}$ & $\begin{array}{l}\text { Completion } \\
\text { time } 35 \mathrm{~ms}\end{array}$ & Yes & No \\
\hline $\begin{array}{l}\text { Bakker et } \\
\text { al 2019[49] }\end{array}$ & $\begin{array}{l}\text { BGP } \\
\text { Flowspec } \\
\text { rules }\end{array}$ & $\sqrt{ }$ & $x$ & $\begin{array}{l}\text { It can not be used } \\
\text { as the only way of } \\
\text { defense }\end{array}$ & $\begin{array}{l}\text { Specify rules on } \\
\text { traffic and it's limi- } \\
\text { tations }\end{array}$ & $\begin{array}{l}\text { effective- } \\
\text { ness is } \\
\text { higher than } \\
\text { Impact }\end{array}$ & Yes & No \\
\hline $\begin{array}{l}\text { Al-Ani et al } \\
2019[50]\end{array}$ & $\begin{array}{l}\text { New } \\
\text { mechanism } \\
\text { against } \\
\text { attacks }\end{array}$ & $\checkmark$ & $x$ & $\begin{array}{l}\text { Can not block all } \\
\text { kinds of packets }\end{array}$ & $\begin{array}{l}\text { It can evade the } \\
\text { OpenFlow firewall }\end{array}$ & $\begin{array}{l}\text { Not } \\
\text { mentioned }\end{array}$ & Yes & No \\
\hline
\end{tabular}

TABle IV. State-of-the-ARt Solutions of Perpetual Echo Attack

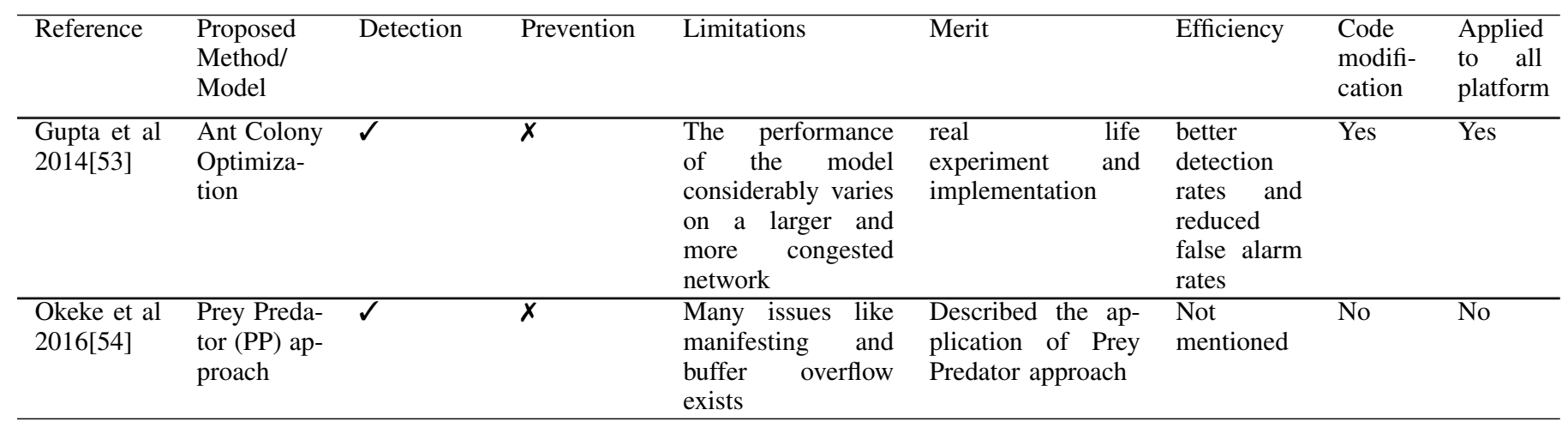

and reply packets. It can be done by changing the payload data so that it contains the attacker's data. So, if anyone uses ICMP messages, he may easily inject malicious data to be destined to the targeted PC. The targeted PC also replies into another ICMP message and returns it back.

In Fig. 7, host A is using an original server through a proxy server. Proxy server may be easily manipulated or authorized by the attacker without the knowledge of the firewall. ICMP messages are used as the payload in this figure. Thus, the information is routed through the attacker's PC without anyone's interference or knowledge.

\section{G. Smurf Attack}

Smurf attack mostly resembles to ping flood attack due to their similar nature of sending ICMP echo request packets. It, being an amplification attack vector [57], accelerates its damage potential through utilizing broadcast network characteristics. It is different than ping flood.

1990 is the year when first smurf attack [58] happened in University of Minnesota. It has effected more than 1 hour and chaining throughout the state. It has completely shut down many computers and servers. As a result, we face loss of 


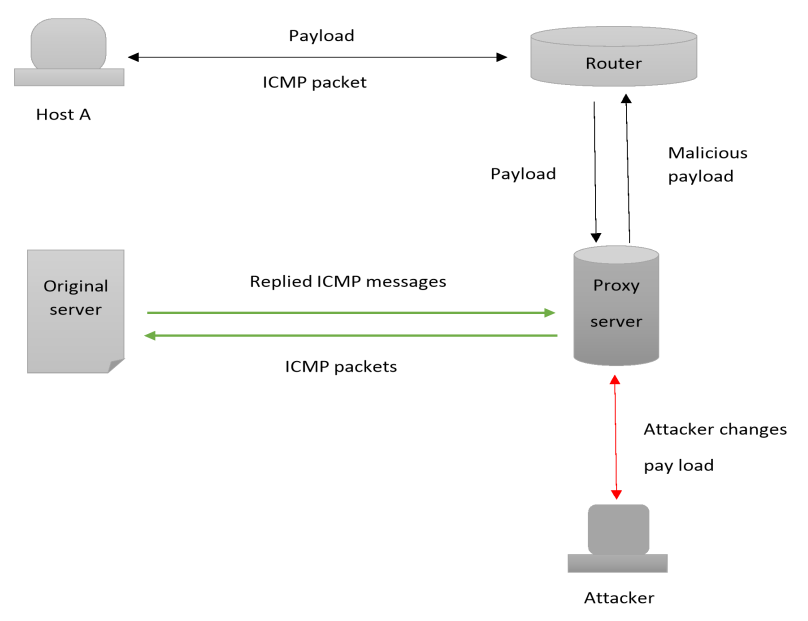

Fig. 7. ICMP Tunneling: Attackers Manipulating ICMP Payload to the Host $\mathrm{A}$ and Receiving Desired Packets.

data and slowdowns. We need to IP broad casting to eliminate Smurf attack.

Following describes the procedure of Smurf attack.

1) The malware generates a network packet attached to a fake IP address. There is a ping message inside the packet. Upon receiving these spoofed packets, the nodes echo back causing a loop eventually leading to a complete denial of service.

2) An insider may directly inject smurf Trojan or it may be accidentally downloaded from forged e-mail or web site. Typically it will remain as it is until activated by the attacker. Consequently, a good number of Smurfs are integrated with rootkits, allows hackers to create backdoor for system access.

Table $\mathrm{V}$ shows state-of-the-art solutions of smurf attack.

\section{H. Router Attack}

Router attacks mainly exploit the vulnerabilities in the networking protocols that lead to inconsistency in software and weak authentication [61]. It normally occurs in the network layer. Attacks [62] [63], that can be a part or origin from router attacks, are mainly brute force and denial of service attacks. When it occurs, it impacts network services and business operations.

2018's report from eSentire shows 539\% of increase in router attackers since 2017. ACI (American consumer institute) also found $84 \% \mathrm{WiFi}$ routers [64] are under risk of cyber attacks or malicious activity. As, people are not aware of security vulnerabilities properly, hackers takes the chance. Black hole routers can detect most types of the router attack and can be modified if the attacker's way changes with time.

In Fig. 8, attacker modified the valid protocol to make new protocol which is malicious and may cause havoc to the system. Some attacks that might disrupt the performance of the router is discussed in the following.

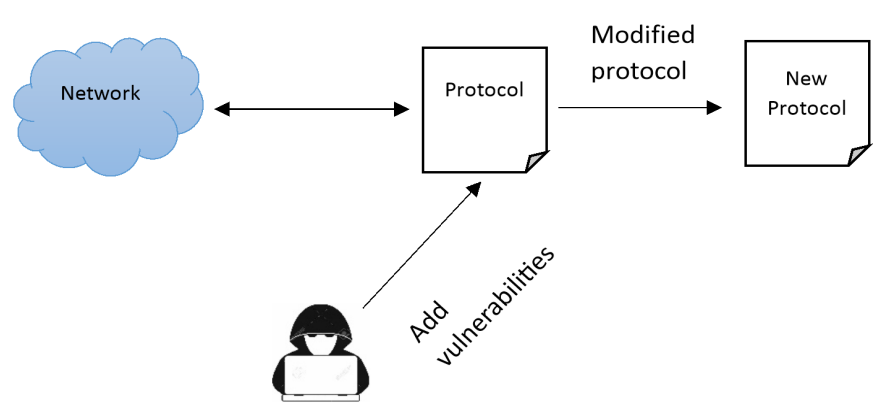

Fig. 8. Router Attack: Attacker Changed the Established Protocol with the Modified Protocol to Ensure Vulnerabilities in Network.

1) Brute Force: Brute force attack is a method where trial and error process is used to get data such as user's password or pin details. In this attack, an automated software generates a large number of close to accurate guesses as to get the desired value. It may be used by the attacker to crack the encrypted data. It may also be used to test the security system of any organization.

2) Packet Mistreating Attack: Router attacks may lead to packet mistreating, mostly like DoS attacks. These packets get mistreated by injecting malicious packets to confuse and overwhelm the system.

3) Routing Table Poisoning: A routing table in a router is not immune to protection and encryption vulnerabilities.Routing table may poison the whole routing routine. These attacks are achieved by manipulating the packet information that are routed through the router.

4) Hit and Run Attacks: This attack is also known as test hacks, and occurs when malicious data is injected into a router. However, the injection process may or may not be successful. The main aim of the is to disturb the environment of a system.

5) Persistent Attacks on Routers: Persistent attack is somewhat similar to hit and run, but in this attack, the injection process becomes successful and the attacker may gain control over the system. After injecting, it will continue it's intended work. The attacker will continue to add malicious packets and confuse the routing table thereafter.

Table VI depicts some existing solutions related to router attack.

\section{Slow and Fast Port Scans Attack}

Port scanning [67] is one of the dangerous network intrusions for getting exploitable communication channel between the attacker and the target. Attacker uses attack to discover service to get into the network. It consists of probing a host in a network for open host. It not only scans but also gathers information that attempts to profile the services running on a potential target. Port scan attack on $4 \mathrm{G}$ router of HUAWEI company [68], detected last year, is one of the recent port scan attack complained by the consumers. Artificial immune systems and fuzzy logic provide more accuracy and also have a robust model compared to other models.

In Fig. 9, attacker uses two scanners to send malicious requests disguised as service messages for scanning system 
TABLE V. State-of-THE-ARt Solutions of SMURf ATtack

\begin{tabular}{|c|c|c|c|c|c|c|c|c|}
\hline Reference & $\begin{array}{l}\text { Proposed } \\
\text { Method/ } \\
\text { Model }\end{array}$ & Detection & Prevention & Limitations & Merit & Efficiency & $\begin{array}{l}\text { Code } \\
\text { modifi- } \\
\text { cation }\end{array}$ & $\begin{array}{l}\text { Applied } \\
\text { to all } \\
\text { platform }\end{array}$ \\
\hline $\begin{array}{l}\text { Jayashree } \\
\text { et al } 2018 \\
\text { [59] }\end{array}$ & $\begin{array}{l}\text { Pattern } \\
\text { Matching } \\
\text { Techniques }\end{array}$ & $\sqrt{ }$ & $x$ & $\begin{array}{l}\text { Accuracy } \\
\text { is less than } \\
\text { desired }\end{array}$ & $\begin{array}{l}\text { Pattern matching tech- } \\
\text { nique for WSN }\end{array}$ & $\begin{array}{l}\text { packet de- } \\
\text { livery ratio } \\
1.3\end{array}$ & Yes & No \\
\hline $\begin{array}{l}\text { Myo et al } \\
2019 \text { [57] }\end{array}$ & $\begin{array}{l}\text { SDN based } \\
\text { technique }\end{array}$ & $\bar{V}$ & $\bar{x}$ & $\begin{array}{l}\text { Real time re- } \\
\text { sults are miss- } \\
\text { ing. }\end{array}$ & $\begin{array}{l}\text { SDN and DDoS attack } \\
\text { is discussed }\end{array}$ & $\begin{array}{l}\text { average } \\
\text { accuracy is } \\
0.97\end{array}$ & Yes & No \\
\hline
\end{tabular}

TABLE VI. State-of-THE-ART SOLUtions OF ROUtER ATtack

\begin{tabular}{|c|c|c|c|c|c|c|c|c|}
\hline Reference & $\begin{array}{l}\text { Proposed } \\
\text { Method/ } \\
\text { Model }\end{array}$ & Detection & Prevention & Limitations & Merit & Efficiency & $\begin{array}{l}\text { Code } \\
\text { modifi- } \\
\text { cation }\end{array}$ & $\begin{array}{l}\text { Applied } \\
\text { to all } \\
\text { platform }\end{array}$ \\
\hline $\begin{array}{l}\text { Ryoki et al } \\
201665\end{array}$ & $\begin{array}{l}\text { An Interest } \\
\text { flow } \\
\text { balancing } \\
\text { method }\end{array}$ & $\sqrt{ }$ & $\checkmark$ & $\begin{array}{l}\text { The router } \\
\text { does not record } \\
\text { information for } \\
\text { further use }\end{array}$ & $\begin{array}{l}\text { Described counter- } \\
\text { measures of IFA }\end{array}$ & Not mentioned & No & No \\
\hline $\begin{array}{l}\text { Yufeng et } \\
\text { al 2018[21] }\end{array}$ & $\begin{array}{l}\text { Distributed } \\
\text { router } \\
\text { shadow }\end{array}$ & $\sqrt{ }$ & $\bar{x}$ & $\begin{array}{l}\text { The connection } \\
\text { between router } \\
\text { shadow and } \\
\text { real router } \\
\text { creates real } \\
\text { difficulties }\end{array}$ & $\begin{array}{lr}\text { Structure } & \text { and } \\
\text { process of router } \\
\text { shadow }\end{array}$ & $\begin{array}{l}\text { minimum } \\
\text { latency and } \\
\text { intended load } \\
\text { reduce }\end{array}$ & No & Yes \\
\hline $\begin{array}{l}\text { Dauod et al } \\
2019[66\end{array}$ & $\begin{array}{l}\text { HT-based } \\
\text { threat } \\
\text { model, } \\
\text { known as } \\
\text { Black Hole } \\
\text { Router } \\
\text { (BHR) }\end{array}$ & $\checkmark$ & $\sqrt{ }$ & $\begin{array}{l}\text { Increased the } \\
\text { waiting time }\end{array}$ & $\begin{array}{l}\text { Real life experi- } \\
\text { ment of black hole } \\
\text { method }\end{array}$ & $\begin{array}{l}10.83 \%, \\
27.78 \% \\
\text { and } 21.31 \% \\
\text { overhead } \\
\text { in area, and } \\
\text { power, and } \\
\text { performance }\end{array}$ & Yes & Yes \\
\hline
\end{tabular}

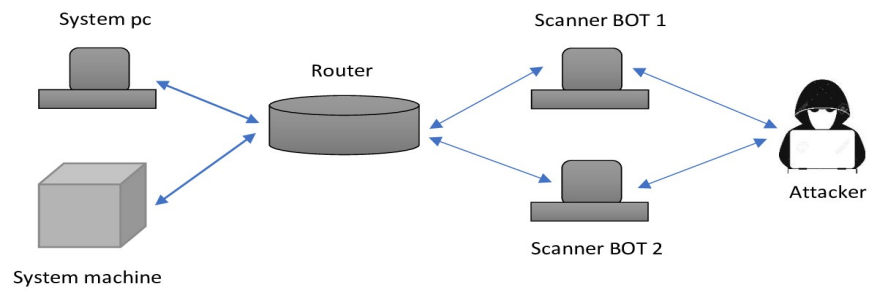

Fig. 9. Scan Attacks: Attackers use BOT Scanners to Scan Data from System's Machine.

devices. These scanners scan the system PC and machine and send results to the attacker.

These attacks are of two types, slow and fast port scan attacks.

1) Slow scan is an active scanning of devices [69] that connects to network where two successive probe messages are spaced in time at least in minutes, but mostly in hours or days. It may take weeks or even months to complete the process. As time passes by, network noise can destroy the scans which might remain unnoticed. Suspicion may be avoided through scanning target slowly by the attacker. Attackers send probe packets in every 5 or 15 minutes. Since slow scan does not create any deviation in the normal traffic, detection of this scan through anomaly and real time detection is very difficult[70].

2) An attacker scans the port in order to change the traffic settings. It can last for minutes or some fractions seconds.

Table VII shows some of the existing solutions of slow and fast port scan.

\section{J. Restricted IP Attack}

It allows an attacker to limit access [76] to the site to an attacker's defined set of IP addresses. If anyone attempts 
(IJACSA) International Journal of Advanced Computer Science and Applications,

TABle ViI. State-of-the-Art Solutions of Slow and Fast Port Scan Attack

\begin{tabular}{|c|c|c|c|c|c|c|c|c|}
\hline Reference & $\begin{array}{l}\text { Proposed } \\
\text { Method/ } \\
\text { Model }\end{array}$ & Detection & Prevention & Limitations & Merit & Efficiency & $\begin{array}{l}\text { Code } \\
\text { modifi- } \\
\text { cation }\end{array}$ & $\begin{array}{l}\text { Applied } \\
\text { to all } \\
\text { platform }\end{array}$ \\
\hline $\begin{array}{l}\text { Mathieu } \\
\text { et al } 2018 \\
\text { [71] }\end{array}$ & $\begin{array}{l}\text { Scan Chain } \\
\text { Encryption }\end{array}$ & $\sqrt{ }$ & $\bar{x}$ & $\begin{array}{l}\text { It is only } \\
\text { applied on } \\
\text { non-modifiable } \\
\text { cores }\end{array}$ & $\begin{array}{l}\text { secure and cost effi- } \\
\text { cient mechanism }\end{array}$ & $\begin{array}{l}100 \% \text { fault } \\
\text { coverage }\end{array}$ & No & Yes \\
\hline $\begin{array}{l}\text { Markus et } \\
\text { al } 2018 \\
\text { [68] }\end{array}$ & $\begin{array}{l}\text { Classification } \\
\text { algorithm }\end{array}$ & $x$ & $\sqrt{ }$ & $\begin{array}{l}\text { It is not applied } \\
\text { on real world } \\
\text { network data. }\end{array}$ & $\begin{array}{l}\text { problem setting and the } \\
\text { underlying flow-based } \\
\text { data are analyzed }\end{array}$ & $\begin{array}{l}\text { Not } \\
\text { sued any } \\
\text { accuracy } \\
\text { measure- } \\
\text { ment }\end{array}$ & Yes & Yes \\
\hline $\begin{array}{l}\text { Manuel et } \\
\text { al } \quad 2019 \\
{[72]}\end{array}$ & $\begin{array}{l}\text { Time- } \\
\text { aware } \\
\text { metrics } \\
\text { in NIDS } \\
\text { evaluations }\end{array}$ & $\sqrt{ }$ & $x$ & $\begin{array}{l}\text { Application of } \\
\text { time-aware ma- } \\
\text { chine learning } \\
\text { models is miss- } \\
\text { ing }\end{array}$ & $\begin{array}{l}\text { Used time-aware eval- } \\
\text { uation metrics for the } \\
\text { early intrusion detec- } \\
\text { tion problem, identify- } \\
\text { ing advantages and dis- } \\
\text { advantages }\end{array}$ & $\begin{array}{ll}0.85 & \text { recall } \\
\text { and } & \text { preci- } \\
\text { sion } & \end{array}$ & Yes & No \\
\hline $\begin{array}{l}\text { Hartpence } \\
\text { et al } 2020 \\
{[74]}\end{array}$ & $\begin{array}{l}\text { Sequential } \\
\text { Neural } \\
\text { Networks }\end{array}$ & $\sqrt{ }$ & $x$ & $\begin{array}{lr}\text { No } & \text { new } \\
\text { algorithm } & \text { is } \\
\text { focused } & \end{array}$ & $\begin{array}{l}\text { sequential NN architec- } \\
\text { ture }\end{array}$ & $\begin{array}{l}99 \% \text { accu- } \\
\text { racy }\end{array}$ & No & No \\
\hline $\begin{array}{l}\text { GUSTAVO } \\
\text { et al } 2020 \\
{[75}\end{array}$ & $\begin{array}{l}\text { Artificial } \\
\text { Immune } \\
\text { Systems } \\
\text { and Fuzzy } \\
\text { Logic }\end{array}$ & $\sqrt{ }$ & $x$ & $\begin{array}{l}\text { Real network } \\
\text { environment } \\
\text { should be } \\
\text { considered }\end{array}$ & $\begin{array}{l}\text { Method comparisons } \\
\text { are discussed with } \\
\text { efficiency }\end{array}$ & $\begin{array}{l}99.9 \% \text { ac- } \\
\text { curacy }\end{array}$ & Yes & No \\
\hline
\end{tabular}

for site access from different IP address not belonging to the list of authorized IP addresses, it will be redirected to an access denied page. No blocks will be rendered, and no JavaScript will be added to the page. The module also has various configuration options including white list or blacklist pages, bypass IP checking by role, and alter the output when blocked. System administrator [77][78] uses this option for enforcing IP-based restrictions to minimize unwanted traffic.

Over 30\% [79] of secure access cloud customers are using the IP address restriction to limit access to corporate resources from a specific set of IP addresses, while still performing strong user authentication.

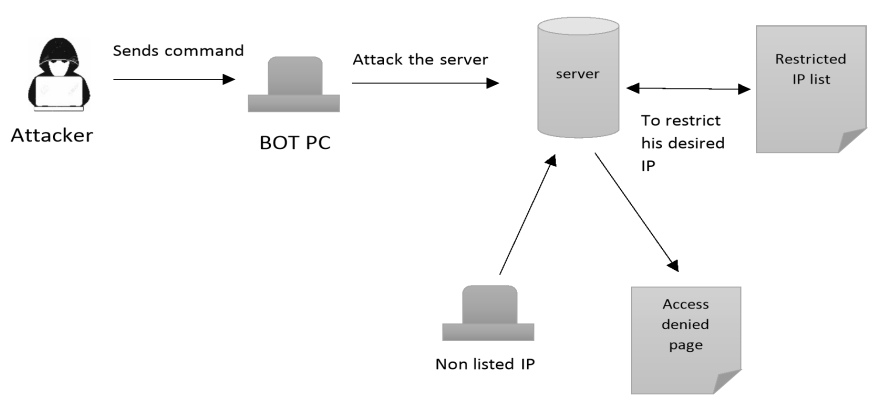

Fig. 10. Restricted IP Attack: Attacker Restricts the IP to Stop Valid users to Visit the Website.

In Fig. 10, attacker sends commands to the BOT PC to attack the main server in order to modify the restrict IP list, so that which PCs are in the restricted list may easily get access in the server.

Table VIII shows some of the existing solutions of the restrict IP option.

\section{K. Address Resolution Protocol(ARP) Attack}

Fig. 11 shows how ARP attack occurs. Let us assume, two hosts PC1 and PC2 are connected through a switch. An attacker, say PC3, is also connected in the same switch. It has modified the MAC address of other hosts with his own MAC address which is EE:EE:EE:FF:FF:FF. In such way, it may get the desired data that is being transferred between two hosts.

ARP spoofing is an attack that occurs when a hacker dispatches fake ARP messages to the local system network. It ends up connecting a hacker's media access control (MAC) address with the IP address of the device that existed in the network. Once the attacker is connected with the system device, he may get his desired information from that device by disguising his own identity. This attack enables attackers to intrude, edit or steal data from the system and also stops data from being transmitted between the system and the host [81].

In April 2018, Cisco Talos released information on the Sea Turtle campaign that hijacked and redirected traffic from more than 40 government and enterprise organizations using ARP 
(IJACSA) International Journal of Advanced Computer Science and Applications,

TABLE VIII. STATE-OF-THE-ART SOLUTIONS OF RESTRICTED IP OPTION

\begin{tabular}{|c|c|c|c|c|c|c|c|c|}
\hline Reference & $\begin{array}{l}\text { Proposed } \\
\text { Method/ } \\
\text { Model }\end{array}$ & Detection & Prevention & Limitations & Merit & Efficiency & $\begin{array}{l}\text { Code } \\
\text { modifi- } \\
\text { cation }\end{array}$ & $\begin{array}{l}\text { Applied } \\
\text { to all } \\
\text { platform }\end{array}$ \\
\hline $\begin{array}{l}\text { Manju et al } \\
2014 \text { [77 }\end{array}$ & $\begin{array}{l}\text { SQL Injec- } \\
\text { tion detec- } \\
\text { tion mecha- } \\
\text { nism }\end{array}$ & $\checkmark$ & $x$ & $\begin{array}{l}\text { Not enough ef- } \\
\text { ficient to inte- } \\
\text { grate in a sys- } \\
\text { tem. }\end{array}$ & $\begin{array}{l}\text { Detects more SQL } \\
\text { injection vulnerabilities } \\
\text { hidden behind the } \\
\text { inadequate blacklist } \\
\text { defense. }\end{array}$ & $\begin{array}{l}\text { Detects } \\
\text { all attack } \\
\text { in the test } \\
\text { case }\end{array}$ & Yes & No \\
\hline
\end{tabular}

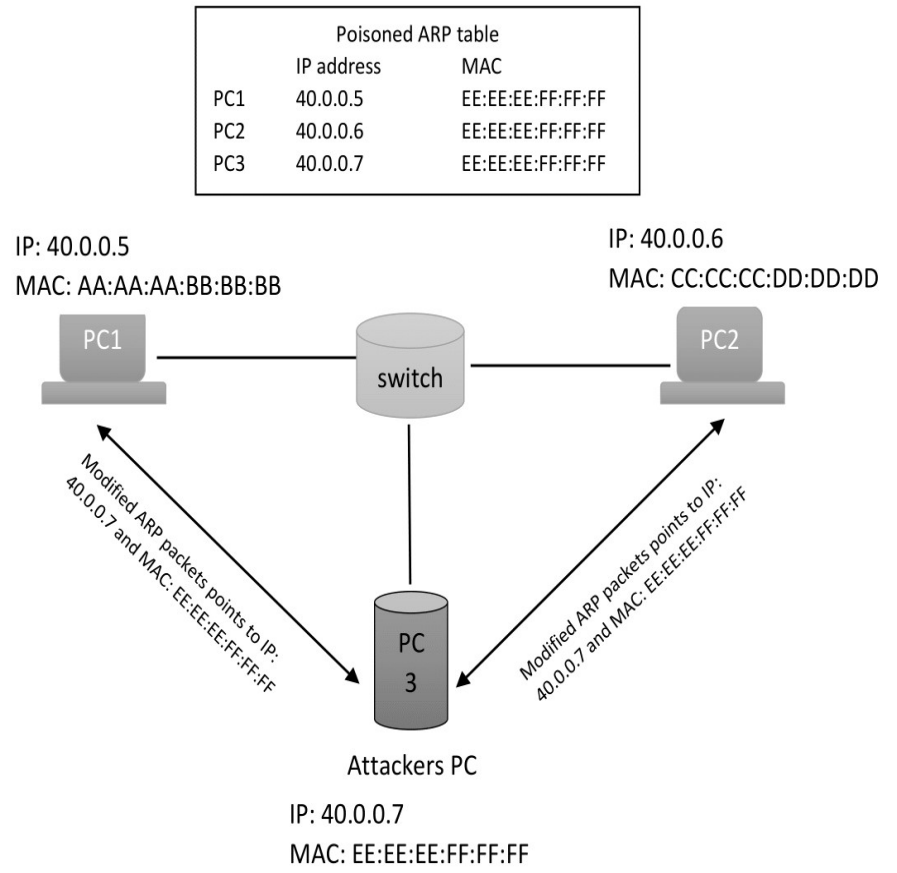

Fig. 11. Occurrence of ARP Attack: Attacker Manipulates ARP Table to Connect as Legitimate Server.

attack [82]. Match prevention is the best way to defend this attack as most ARP replies can be detected by this model.

ARP intrusion may result in the following types of attacks:

1) Session Hijacking: It is a cyber security attack on a user session over a network. In this attack, attackers exploit ARP spoofing attack to get one session ID and steal their sensitive information.

2) Man in the Middle Attack: This attack also employs ARP spoofing to disturb the traffic from a user and manipulates it to get access to user sessions. This attack re-routes the network traffic between the host and the attacker. So, the attacker will transmit the received packets to the desired destination. Hence, the communication between two original hosts is not disrupted and the sniffing process may go unnoticed.

3) Cloning Attack: In this attack, hacker himself change his IP and MAC to look exactly like the target host. Once the process is done, there will be two hosts having same address. The target host gets confused and the attacker takes the advantage as real one.

As ARP intrusion can have many forms, detection can be difficult and needs perfection. We can have lots of false alarms, which could lead the team ignoring the alarms without investigation. The most simple way to get rid of this intrusion is to use static, read-only entries for the services in the ARP cache. There exists a good number of research efforts presenting intelligent methods to get rid of this intrusion.

Table IX shows some effective detection and prevention systems of ARP intrusion.

\section{Ping of Death Attack}

A ping of death (PoD) sends a malicious ping to a computer. The maximum size of an IPv6 packet including the IP header is 65,535 bytes. Many ancient computers [88] cannot handle this large size of packets and will crash if it receives one. This attack exploits early TCP/IP implementations including Windows, Mac, Linux and other network devices like router and fax etc. Since sending packets in large form causes IP fragmentation by attacker, targeted system can get lot of ICMP packets via ping without waiting for the reply. Once the system becomes vulnerable to this attack, other attacks may dig in like Trojan horse. Cloud flare protection can demolish the PoD attacks before they reach the targeted host. There is no specific works related to this attack. Certainly, some DDoS attack related paper added the solution of this intrusion as a small part of it. The low rate [89] "Ping of death" attack, dubbed BlackNurse, effects firewalls from Cisco, Zyxel, and possibly Palo Alto in 2016.

Fig. 12 shows a general model of such attack. In this figure, BOT have sent ICMP spoofed ping messages in the network. The server will broadcast ping flood resulting in other PCs connected with the server unable to work. This mostly happens on the data link layer. This attack is less common today as many computers are immune to this attack. Generally in this attack, attacker transmits malformed or oversized packets exploiting ping command that results in system crash.

One of the solutions is to add a verification to reassemble the function to make sure data packets size don't get maximized. Other solution can be creating a memory buffer to handle the space of every incoming packets . Cloud flare 
TABLE IX. STATE-OF-THE-ART SOLUTIONS OF ARP INTRUSION

\begin{tabular}{|c|c|c|c|c|c|c|c|}
\hline Reference & $\begin{array}{l}\text { Proposed } \\
\text { Method/ } \\
\text { Model }\end{array}$ & Prevention & Limitations & Merit & Efficiency & $\begin{array}{l}\text { Code } \\
\text { modifi- } \\
\text { cation }\end{array}$ & $\begin{array}{l}\text { Applied } \\
\text { to all } \\
\text { platform }\end{array}$ \\
\hline $\begin{array}{l}\text { Ghazi et al. } \\
2016 \text { 83 }\end{array}$ & $\begin{array}{l}\text { ARP } \\
\text { table, ARP } \\
\text { filtering, } \\
\text { authenticat- } \\
\text { ing }\end{array}$ & $\sqrt{ }$ & $\begin{array}{lrr}\text { All ways of } & \text { ARP } \\
\text { spoofing is } & \text { not } \\
\text { discussed } & & \text { and } \\
\text { detected. } & & \\
\end{array}$ & $\begin{array}{l}\text { Defense implemen- } \\
\text { tation }\end{array}$ & $\begin{array}{l}\text { Not } \\
\text { mentioned }\end{array}$ & Yes & Yes \\
\hline $\begin{array}{l}\text { Sweta et al. } \\
2018 \text { 84 }\end{array}$ & $\begin{array}{l}\text { Secondary } \\
\text { ARP table }\end{array}$ & $\sqrt{ }$ & $\begin{array}{l}\text { Time interval } \\
\text { between hosts is } \\
\text { fixed. Authorized } \\
\text { connection may } \\
\text { take longer time } \\
\text { can be concluded } \\
\text { as attack. }\end{array}$ & $\begin{array}{l}\text { Real time imple- } \\
\text { mentaion }\end{array}$ & $\begin{array}{l}\text { Not } \\
\text { mentioned }\end{array}$ & Yes & Yes \\
\hline $\begin{array}{l}\text { Jing et al. } \\
2019 \mid 32\end{array}$ & $\begin{array}{l}\text { ARP reply } \\
\text { message } \\
\text { process in } \\
\text { OpenFlow } \\
\text { platform }\end{array}$ & $\bar{x}$ & $\begin{array}{l}\text { The system is not } \\
\text { flexible enough to } \\
\text { integrate }\end{array}$ & $\begin{array}{l}\text { Discussed new fea- } \\
\text { tures in OpenFlow } \\
\text { network }\end{array}$ & $\begin{array}{l}\text { Min. } \\
\text { Min.5679.76 } \\
\text { Max.8307.89 } \\
\text { Avg. } \\
7919.66 \\
\text { S.D } 404.60\end{array}$ & Yes & Yes \\
\hline $\begin{array}{l}\text { Sanguankot- } \\
\text { chakorn } \\
\text { et al. } \\
201985 \text { a }\end{array}$ & $\begin{array}{l}\text { Hybrid } \\
\text { controller }\end{array}$ & $x$ & $\begin{array}{l}\text { Detecting Switched } \\
\text { DDoS attack is tak- } \\
\text { ing around } 9 \text { sec- } \\
\text { onds which is re- } \\
\text { ally slow. }\end{array}$ & $\begin{array}{l}\text { Discussed } \\
\text { Controller } \\
\text { mitigation process }\end{array}$ & $\begin{array}{l}\text { Entropy } \\
\text { falls } 1 \text { to } 0 \\
\text { with time }\end{array}$ & Yes & Yes \\
\hline $\begin{array}{l}\text { Sanguankot- } \\
\text { chakorn } \\
\text { et al. } \\
2019 \text { 86 }\end{array}$ & $\begin{array}{l}\text { A non- } \checkmark \\
\text { cryptography- } \\
\text { based and } \\
\text { called } \\
\text { MR-ARP }\end{array}$ & $x$ & $\begin{array}{l}\text { It takes longer time } \\
\text { to determine the se- } \\
\text { cure path }\end{array}$ & $\begin{array}{l}\text { Analyzed } \\
\text { Mitigation } \\
\text { technique }\end{array}$ & $\begin{array}{l}\text { Not } \\
\text { mentioned }\end{array}$ & Yes & Yes \\
\hline $\begin{array}{l}\text { Al-An et al. } \\
2020 \mid 87\end{array}$ & $\begin{array}{ll}\text { Match- } & X \\
\text { Prevention } & \end{array}$ & $\sqrt{ }$ & $\begin{array}{l}\text { the bandwidth con- } \\
\text { sumption of Match } \\
\text { Prevention is } 18 \% \\
\text { higher }\end{array}$ & $\begin{array}{l}\text { Discussed security } \\
\text { challenges }\end{array}$ & $\begin{array}{l}100 \% \text { suc- } \\
\text { cess rate }\end{array}$ & Yes & Yes \\
\hline
\end{tabular}

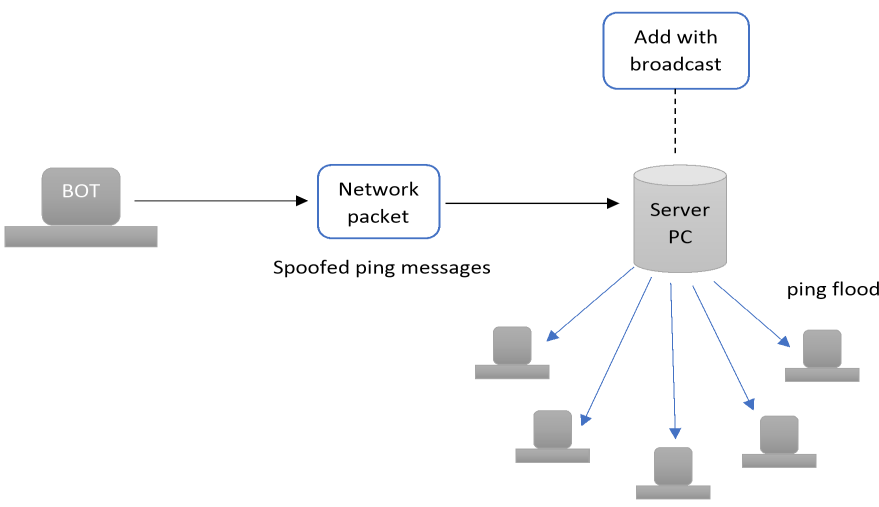

Fig. 12. Ping of Death: Spoofed Ping Messages Add with the Broadcast IP of the Server to Manipulate clients PC.

protection can demolish the PoD attacks before making any harm to the PC [90].

There is no specific works related to this attack. Certainly, some DDoS attack related paper added the solution of this intrusion as a small part of it.

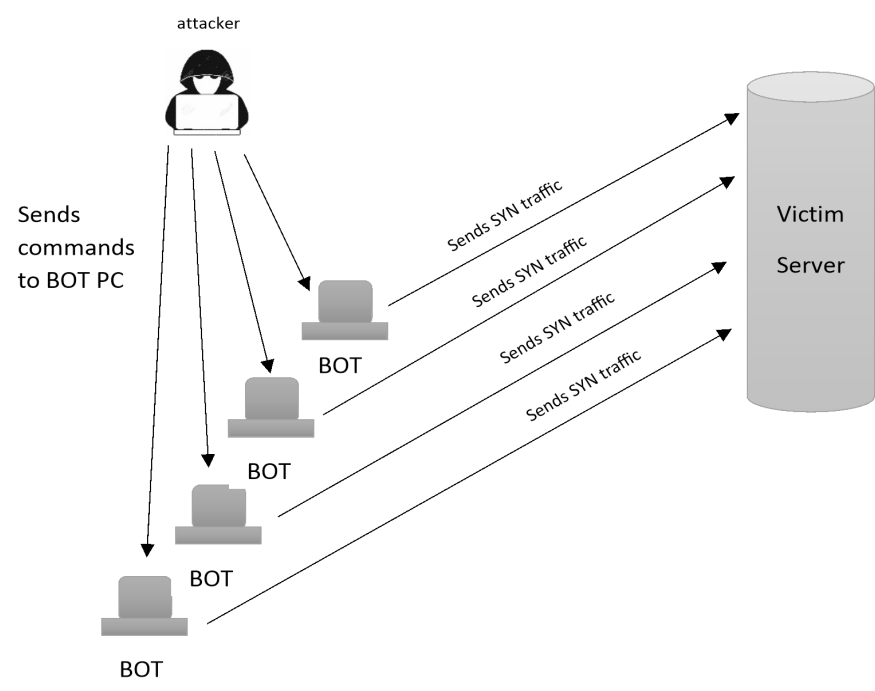

Fig. 13. SYN Flood Attack: Attacker Sends Command to BOT PC Sends SYN Traffic to Server. 
TABLE X. STATE-OF-THE-ART SOLUTIONS OF SYN FLOOD ATTACK

\begin{tabular}{|c|c|c|c|c|c|c|c|c|}
\hline Reference & $\begin{array}{l}\text { Proposed } \\
\text { Method/ Model }\end{array}$ & Detection & Prevention & Limitations & Merit & Efficiency & $\begin{array}{l}\text { Code } \\
\text { modifi- } \\
\text { cation }\end{array}$ & $\begin{array}{l}\text { Applied } \\
\text { to all } \\
\text { platform }\end{array}$ \\
\hline $\begin{array}{l}\text { Hussain } \\
\text { et al } \\
2016 \\
91\end{array}$ & $\begin{array}{l}\text { Three Way } \\
\text { Counter } \\
\text { Algorithm } \\
\text { for Attack } \\
\text { Detection }\end{array}$ & $\sqrt{ }$ & $x$ & $\begin{array}{l}\text { Cloud security } \\
\text { is not justified }\end{array}$ & $\begin{array}{l}\text { HoneyPot method } \\
\text { is emphasized }\end{array}$ & $\begin{array}{l}\text { Attack detection } \\
\text { rate of Tcp port } \\
60 \%\end{array}$ & No & No \\
\hline $\begin{array}{l}\text { Kshirsagar } \\
\text { et al } \\
2016 \\
92\end{array}$ & $\begin{array}{l}\text { System } \\
\text { architecture } \\
\text { for efficient } \\
\text { detection }\end{array}$ & $\sqrt{ }$ & $x$ & $\begin{array}{l}\text { Authors have } \\
\text { used only } 4 \\
\text { features to } \\
\text { detect attack } \\
\text { which is not } \\
\text { efficient }\end{array}$ & $\begin{array}{l}\text { load of CPU is } \\
\text { minimized after } \\
\text { The attack }\end{array}$ & $\begin{array}{l}\text { Cpu load value } \\
\text { ranges from } 8-11 \% \\
\text { after detection }\end{array}$ & Yes & Yes \\
\hline $\begin{array}{l}\text { Kumar } \\
\text { et al } \\
2018 \\
993\end{array}$ & SAFETY & $\sqrt{ }$ & $\bar{x}$ & $\begin{array}{l}\text { Victims from } \\
\text { multiple } \\
\text { destination can } \\
\text { not be detected }\end{array}$ & $\begin{array}{l}\text { SAFETY brings } 13 \\
\text { percent regarding } \\
\text { processing delay } \\
\text { experienced by a } \\
\text { legitimate node }\end{array}$ & $\begin{array}{l}100 \% \text { TPR while } \\
\text { has approximately } \\
27 \% \text { FPR }\end{array}$ & Yes & Yes \\
\hline $\begin{array}{l}\text { Bae et } \\
\text { al } 2018 \\
94\end{array}$ & $\begin{array}{l}\text { DDoS Cyber- } \\
\text { Shelter model }\end{array}$ & $\sqrt{ }$ & $x$ & $\begin{array}{l}\text { Authentication } \\
\text { data can get } \\
\text { access to the } \\
\text { service even } \\
\text { during the } \\
\text { attacks are } \\
\text { made. Data can } \\
\text { be manipulated }\end{array}$ & $\begin{array}{l}\text { a cost-effective } \\
\text { way }\end{array}$ & $\begin{array}{lr}\text { lowest } & \text { false } \\
\text { positive } & \text { rate } \\
\text { of } 0.0003 \% & \text { at } \\
\text { maximum } & \end{array}$ & Yes & Yes \\
\hline $\begin{array}{l}\text { Zhong } \\
\text { et al } \\
2018 \\
95\end{array}$ & $\begin{array}{l}\text { Three modules, } \\
\text { such as sniffer } \\
\text { module, analy- } \\
\text { sis module and } \\
\text { active defense } \\
\text { module }\end{array}$ & $\sqrt{ }$ & $\sqrt{ }$ & $\begin{array}{l}\text { Most network } \\
\text { administrators } \\
\text { do not have set } \\
\text { up such rules, it } \\
\text { gives potential } \\
\text { attackers the } \\
\text { convenience of } \\
\text { attacks }\end{array}$ & $\begin{array}{l}\text { provide reference } \\
\text { for tracking SYN } \\
\text { flood attack }\end{array}$ & $\begin{array}{l}\text { Network } \\
\text { administrators } \\
\text { are no longer } \\
\text { required }\end{array}$ & Yes & Yes \\
\hline $\begin{array}{l}\text { Khalid } \\
\text { et al } \\
2019 \\
96\end{array}$ & $\begin{array}{l}\text { SYN Flood } \\
\text { Attack } \\
\text { Detection } \\
\text { Based } \\
\text { on Bayes } \\
\text { Estimator } \\
\text { (SFADBE) }\end{array}$ & $\sqrt{ }$ & $x$ & $\begin{array}{l}\text { Bandwidth is- } \\
\text { sue exists }\end{array}$ & low cost and robust & threshold is 8.0 & Yes & Yes \\
\hline $\begin{array}{l}\text { Dang et } \\
\text { al } 2019 \\
97\end{array}$ & $\begin{array}{l}\text { SSP (a } \\
\text { coordination } \\
\text { of the SDN } \\
\text { Open-flow } \\
\text { switch) }\end{array}$ & $\sqrt{ }$ & $\bar{x}$ & $\begin{array}{l}94 \text { percent } \\
\text { accuracy which } \\
\text { is not good } \\
\text { enough for } \\
\text { integration in a } \\
\text { system }\end{array}$ & $\begin{array}{l}\text { SSP improves the } \\
\text { successful connec- } \\
\text { tion rate and aver- } \\
\text { age connection re- } \\
\text { trieval time }\end{array}$ & $\begin{array}{l}\text { SSP can reduce the } \\
\text { number of HOCs } \\
\text { by } 68 \% \text { in case of } \\
100 \mathrm{pkt} / \mathrm{s} \text { rate, and } \\
\text { by } 86 \% \text { in case of } \\
500 \mathrm{pkt} / \mathrm{s} \text {. }\end{array}$ & Yes & Yes \\
\hline $\begin{array}{l}\text { Evmorfos } \\
\text { et al } \\
2020 \\
{[98}\end{array}$ & $\begin{array}{l}\text { Random } \\
\text { Neural } \\
\text { Network with } \\
\text { Deep Learning }\end{array}$ & $\sqrt{ }$ & $x$ & $\begin{array}{l}\text { Neural } \\
\text { Network's } \\
\text { recurrent } \\
\text { structure needs } \\
\text { to improve }\end{array}$ & $\begin{array}{l}\text { substantially better } \\
\text { attack } \\
\text { and detection } \\
\text { lower false alarm } \\
\text { rate }\end{array}$ & $\begin{array}{ll}\text { Accuracy } & \text { False } \\
80.7 \% & \end{array}$ & No & No \\
\hline
\end{tabular}

\section{SYN Flood Attack}

In a SYN flood attack, the attacker does not respond with the expected ACK to the server. Also, the attacker might spoof the source IP address in the SYN packets which causes the server to transmit SYN-ACK to a fake IP address. Due to the creation of a half open connection [99] [91], the malicious client consumes server resources unnecessarily and prohibits the server in establishing connections to the other clients. One of the ways of mitigating this attack is the use of Cloud flare between the target server and the SYN flood.

A well-documented DDOS attack was introduced in 1996 by panix. In 2005 [100] [101], the website of this company got hijacked again in the period of holiday. It took off their sleeps to get everything back together.

Fig. 13 depicts a sample scenario of this attack. In this 
figure, by sending initial connection request through SYN packets, the hacker makes the ports of the Victim server overwhelmed.

Some state-of-the-art solutions of SYN floods attack are presented in Table $\mathrm{X}$

\section{N. Malformed Attack}

Malformed packet consists of malware or other malicious elements. In this attack, a BOT PC sends incorrectly formed packets to the victim to crash the system by receiving attacker instruction. The massive combination of DDOS and IoT attacks have been blown up in late 2016. This is the largest one till now. It has extremely terrifying capability of exploiting about $1.2 \mathrm{~TB}$ per seconds. Best way to filter this attack is to allow legitimate traffic and discard floods of packets [102] like ICMP or UDP.

Categorizing it as follows: (i) IP address malformed attack and, (ii) IP packet malformed attack.

1) IP address malformed attack contains the same source and destination IP address which confuses the target system resulting in system crash.

2) In this attack, system is forced to process and waste additional time due to randomizing the optional fields in IP packet along with setting all QoS bit to 1 [103]. This attack might lead to the system crash if combined with multiple attackers [104].

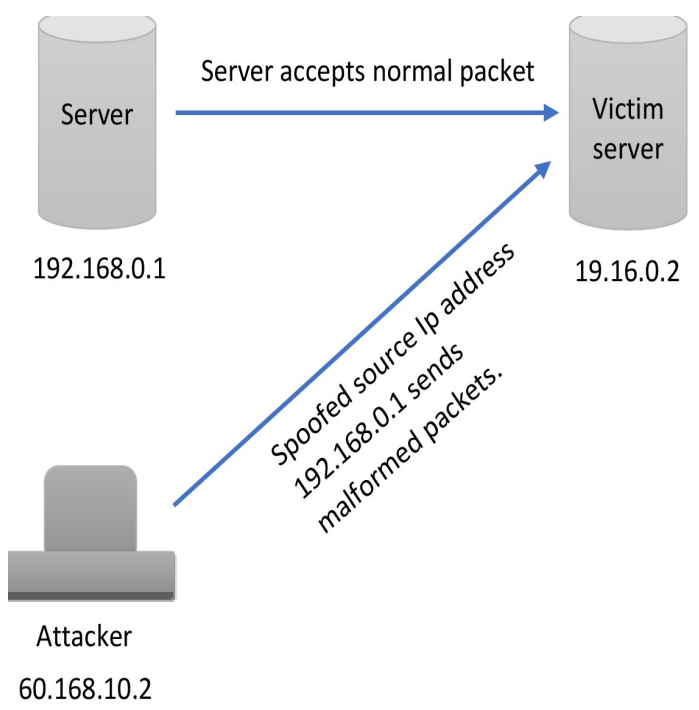

Fig. 14. Malformed Attack: Attacker Spoofed the IP Address to Send Malformed Packet to the Victim Server.

In the Fig. 14 attacker changes his IP address to source IP address 192.168.0.1 and acts as an legitimate server. By establishing connection with the server it sends malformed packet. Packet malforming leads to packet manipulation. A larger ping more than 65,535 bytes [105] is enough to conduct a attack. So attackers send it by fragments. If the victim tries to reassemble it, they will face oversized packet or memory over flow. It could crush PC or servers in the mean time
Some existing solutions related to this attack is enlisted in Table XI.

\section{Extrusion Events}

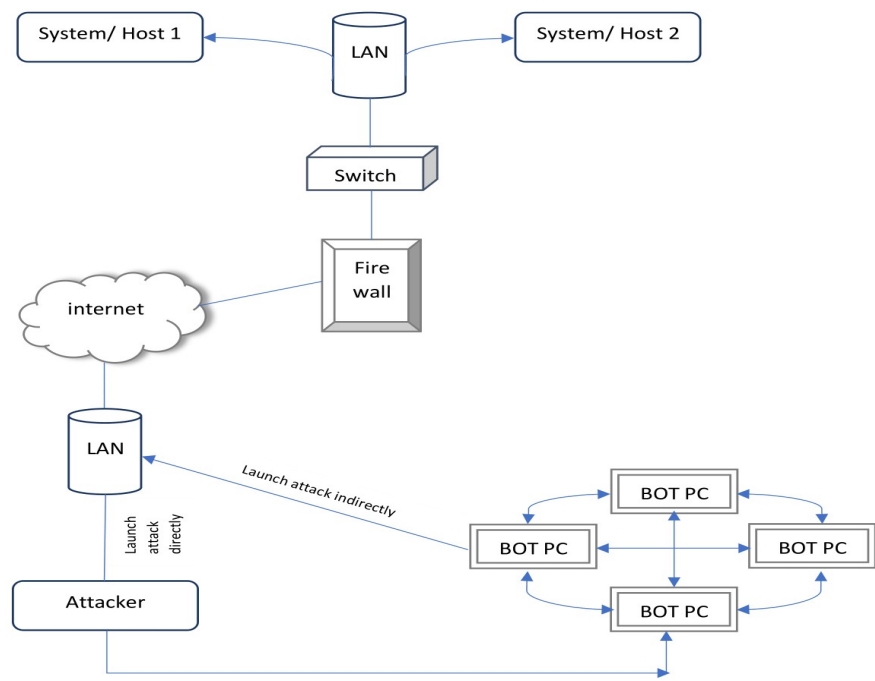

Fig. 15. A Generalized Model of Occurrence of an Extrusion Event.

In this section, we excavate the extrusion events. In what follows, we present their definitions, explain how they occur and outlined the possible solutions with necessary figures and tables, wherever applicable. As stated earlier, extrusion event might bring vulnerability to the remote system device by getting injected with malware or by opening a malicious web page etc.

Fig. 15 shows a generalized model of an extrusion in a system. Basically, in Fig. 15. two hosts are connected with the same LAN. LAN connects to the switch and switch connects to the internet. Firewall is the barrier between the attacker and the target. Also, numerous attackers and BOT PC (created by attackers) are connected with the internet through LAN. If any user of that host clicks on malicious websites, or opens malware related software, then extrusion may occur. As numerous attackers frequently upload malware through internet and also send phishing e-mails, it is highly probable to get infected by clicking malicious links or downloading malicious files. This section describes all possible extrusion events and the related existing counter measures.

\section{A. Supply Chain Attack}

According to November2018 study by Opus Ponemon Institute, 59 percent of organizations in UK and US has already experienced data tempering and compromised security issues by their third party stakeholders [107].

Fig. 16 shows a general model of a supply chain attack. In this figure, attacker changes the script of any targeted server which makes the server compromised. Eventually, the malicious or compromised server makes other server compromised and thus the chain continues.

Due to the repeated attack on different servers, it is almost impossible to detect it. Other attacks only target the victim 
TABLE XI. State-OF-The-ARt Solutions of Malformed AtTack

\begin{tabular}{|c|c|c|c|c|c|c|c|c|}
\hline Reference & $\begin{array}{l}\text { Proposed } \\
\text { Method/ } \\
\text { Model }\end{array}$ & Detection & Prevention & Limitations & Merit & Efficiency & $\begin{array}{l}\text { Code } \\
\text { modifi- } \\
\text { cation }\end{array}$ & $\begin{array}{l}\text { Applied } \\
\text { to all } \\
\text { platform }\end{array}$ \\
\hline $\begin{array}{l}\text { Patil et al } \\
2019 \text { [105 }\end{array}$ & $\begin{array}{l}\text { Threshold } \\
\text { value set } \\
\text { for detect } \\
\text { malformed } \\
\text { packet }\end{array}$ & $\sqrt{ }$ & $x$ & $\begin{array}{l}\text { The proposed } \\
\text { mechanism } \\
\text { misapprehends some } \\
\text { malformed packets. } \\
\text { However, they are } \\
\text { dropped as excess } \\
\text { flood packets due to } \\
\text { crossing the threshold } \\
\text { limit }\end{array}$ & $\begin{array}{l}\text { All kinds of } \\
\text { flood attack } \\
\text { can be detected }\end{array}$ & $\begin{array}{l}\text { Not } \\
\text { mentioned }\end{array}$ & No & Yes \\
\hline \begin{tabular}{l}
\multicolumn{2}{l}{ Venugopal } \\
et al 2019 \\
{$[106]$}
\end{tabular} & $\begin{array}{l}\text { Generates } \\
\text { ACL }\end{array}$ & $\bar{\checkmark}$ & $\bar{x}$ & $\begin{array}{l}\text { Legitimate IP } \\
\text { addresses requires } \\
\text { to be minimized to run } \\
\text { the system }\end{array}$ & $\begin{array}{l}\text { Detailed DDos } \\
\text { attack }\end{array}$ & $\begin{array}{l}\text { Not } \\
\text { mentioned }\end{array}$ & Yes & Yes \\
\hline
\end{tabular}

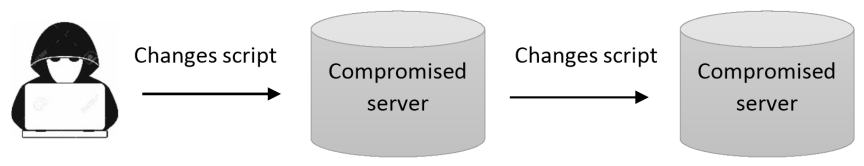

Fig. 16. A Chain System of Attack: an Attacker Changes the Script of the Server to Manipulate System

computer, but in this attack, the victim is not the ultimate target of the attack, rather stepping a stone to other networks. This attack mainly occurs on application layer. The 2013 attack against Target is the classic example of a supply chain attack. As the attack is new and very difficult to detect, no such paper has discussed about the solution to it.

\section{B. Destruction of Services (DeOS) Attack}

A destruction of services targets the entire organization's ability to recover from the attack afterwards. It is meant to damage the maximum amount possible, resulting in data loss, service disruptions and cost of data recovery. It puts business in such a position that either they have to rebuild their architecture from scratch or pay the money to the attacker.

In its 2017 Midyear Cybersecurity Report, Cisco said the rapid spread of WannaCry, for example, foreshadowed the emergence of what it is termed "destruction of service" (DeOS) attacks, which could present an existential threat and leave businesses completely unable to recover.

To defend against this attack, a system needs to check regular penetration test results, hiring more cyber security staffs and decreasing mean time to detect man in the middle destruction statistics. The quicker the threat is detected, less the damage occurs throughout the system.

In the Fig. 17 attacker commands the BOT PC's to attack the website of the organization to destroy the back up file or the database.

The two most common points of entry for attackers are through known exploitable vulnerabilities and acquired administrator credentials. This attack includes Cisco's 2017 that made Cisco worry to use creative ideas to mitigate the attack.

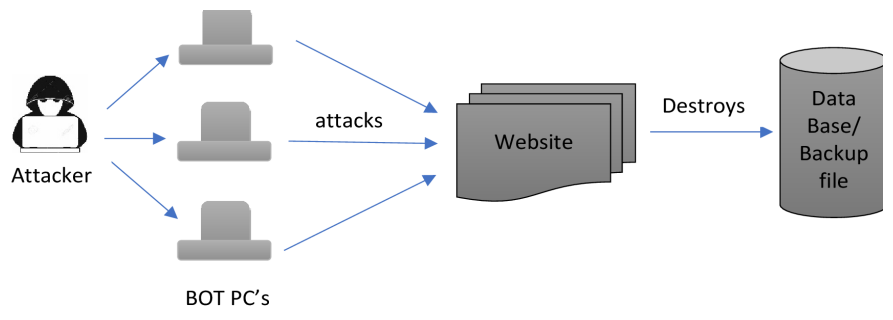

Fig. 17. DeOS Attack: Attacker Attacks the Main Structure of the Organization.

The common default passwords, common default setting is also an concerned issue.

Popular destruction-of-service attack vectors include:

1) Business Email Compromise (BEC): Business email compromise attacks uses the ID of someone on the particular network to trick the victim into sending money or info to the attacker. The most common victims are those who use wire transfers to send money to international clients.

2) Cyberwarfare: Cyberwarefare generally refers to attacks that relate to cybernet. In every case, it has been observed that a terrorist group or hacker groups aimed at a particular nation or political organization to do their work done. This event is also new to the network system, and no specific solution has come out.

\section{Distributed Denial of Services (DDoS) Attack}

DDoS attack is a fraudulent attempt to make any service unavailable to the users. It can be launched from globally distributed compromised devices, also known as Botnet. It is hard to differentiate legal user traffic from malicious trafficn [108] when dispatched across many points of origin. This may cause long-term reputation damage.

The Google attack in 2017, the AWS DDoS attack in 2020, the Mirai Krebs and OVH DDoS attacks in 2016, the Mirai Dyn DDoS attack in 2016, the Six Banks DDoS attack in 2012 are the most famous DDoS attacks that caused most harm to the organization. Traceback approach has both prevention and 


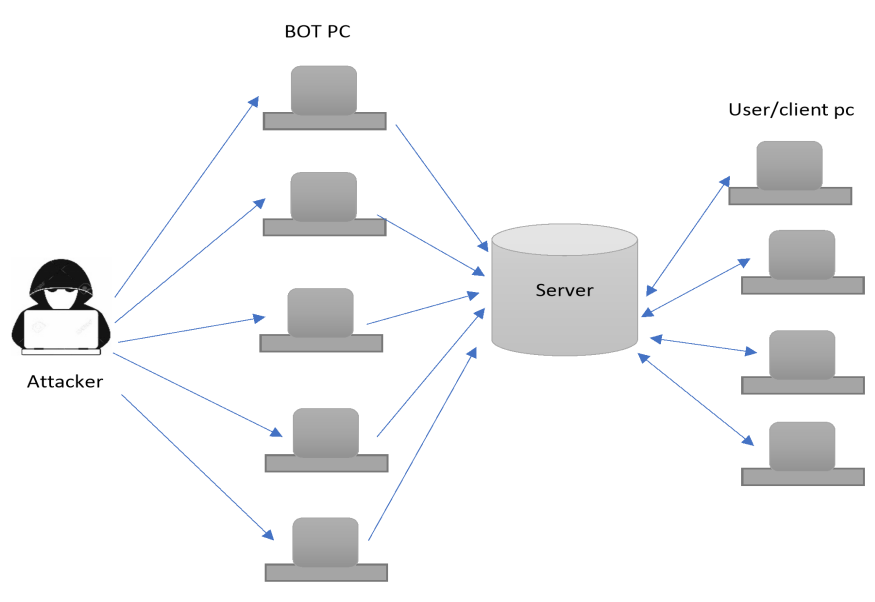

Fig. 18. DDoS Attack: Several Bot PCs Compromised the Server to Attack the Target.

detection method and also has an efficient code enhancement system.

Fig. 18 depicts a model of how DDoS occurs. In this figure, the attacker commands the BOT computer to send illegitimate traffic in order to flood the system server PC. From the system server PC, users/clients also get illegitimate traffic, causing the system unavailable.

It can be categorized into three types [109], which are:

1) Volume Based Attack: This attack is related with ICMP flood attack, UDP flood attack and also spoofed packet flood attack. Attacker intends to change the value of the bandwidth of victim's site. The parameter of this attack is measured in bits/second.

2) Protocol Attack: This type of attack is related with fragment packet attack, syn flood attack, ping of death and smurf attack and many more. Here, the attacker attacks attacks actual server data, communicating devices between hosts, firewalls as well as load balancer. The parameter of this attack is measured in packet/second.

3) Application Layer Attack: This attack is related with Post/Get php flood attack, slow attack and many more. Mainly the attacker targets the victim's windows or OpenBSD vulnerabilities. Attacker makes the victim believed that the request is innocent and legitimate. The main goal of the attack is to crash the main server of the system. The magnitude of this attack is measured in requests per second.

Solutions related to this event are presented in Table XII.

\section{Phishing Attack}

Phishing attack targets the victim's computer through mails, messages or via link by pretending to be a legitimate person or organization to lure the victim. By doing these, the attacker gets to know the victim's personal sensitive data [115] for example, ID card information, credit card information and passwords, etc.

In 2020, Doharty associate claimed their customer faced one phish, two phish, red phish, blue phish in the name of phishing attacks. They also fell for it and gave away their password details. Support vector machine and Naive Bayes algorithm have approximately $100 \%$ efficiency to defend any kind of phishing attacks.

Usually, the attacker performs the phishing attack using one of the following ways:

1) The attacker can hand over the important information.

2) Attacker spams out the phishing messages to many people, so that at least some people will be the customers of some specific bank or organization.

Phishing attack may be categorized as follows.

1) Spear Phishing: Spear phishing may attack a particular person of an organization often with content tailor made only for the victim. The attacker requires sufficient knowledge about the organization to produce such content. The content may relate to victim's colleagues, names and relationship with employees. With this kind of data, attacker may generate a trusted email.

2) Clone Phishing: The attacker attaches a malicious link or attachment utilizing a previously delivered valid email. Once the user clicks on the link, he becomes the victim. Then the attacker gets his desired information from that victim using certain measurements. Victim may give organization's confidential data to the attacker in some cases [116].

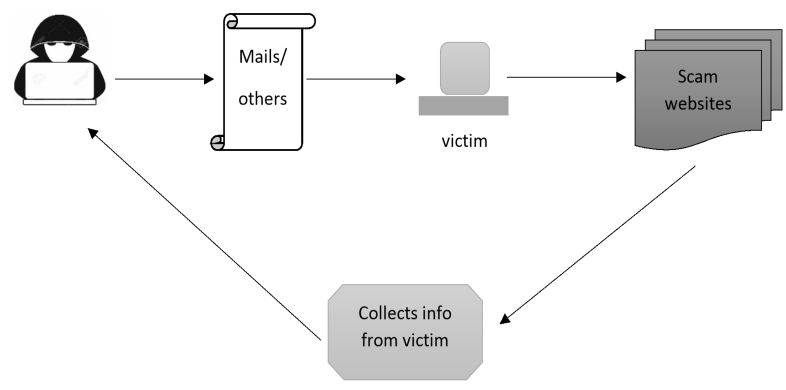

Fig. 19. Scamming a Victim's Computer using Phishing Attack: Attackers Send Mails to Victim's Computer to collect Information by Clicking on Scam Website

Fig. 19illustrates how a phishing attack takes place. In this figure, attacker sends malicious e-mails or other documents. If the user clicks on a link provided by an attacker given through a message, then he may provide his username, password, etc. to that website which may resemble as real but actually is a malicious site. Now attacker may enter into his account. Most of the messages are sent to the HR staff with the infected file that disguised as a job seeker's resume, for instance [117]. Most of these attachments are often zip files, or documents with embedded code. It plays a significant role in other attacks like Trojan and ransomware.

Some state-of-the-art solutions to this attack are presented in Table XIII.

\section{E. URL Poisoning Attack}

URL poisoning attack, also addressed as location poisoning, tracks down any web user's page sequence or information 
(IJACSA) International Journal of Advanced Computer Science and Applications,

TABLE XII. STATE-OF-THE-ART SOLUTIONS OF DDoS

\begin{tabular}{|c|c|c|c|c|c|c|c|c|}
\hline Reference & $\begin{array}{l}\text { Proposed } \\
\text { Method/ } \\
\text { Model }\end{array}$ & Detec-tion & Preven-tion & Limitations & Merit & Efficiency & $\begin{array}{l}\text { Code } \\
\text { modifi- } \\
\text { cation }\end{array}$ & $\begin{array}{l}\text { Applied } \\
\text { to all } \\
\text { platform }\end{array}$ \\
\hline $\begin{array}{l}\text { Alan et al } \\
2016 \text { [109] }\end{array}$ & $\begin{array}{l}\text { Artificial } \\
\text { Neural } \\
\text { Network } \\
\text { (ANN) } \\
\text { algorithm }\end{array}$ & $\bar{x}$ & $\sqrt{ }$ & $\begin{array}{l}\text { It is not de- } \\
\text { signed for en- } \\
\text { crypted packets }\end{array}$ & $\begin{array}{l}\text { detect DDoS attacks } \\
\text { based on specific char- } \\
\text { acteristic features (pat- } \\
\text { terns) }\end{array}$ & $\begin{array}{l}98 \% \text { accu- } \\
\text { racy }\end{array}$ & Yes & Yes \\
\hline $\begin{array}{l}\text { Mehr et al } \\
2019 \text { [111] }\end{array}$ & $\begin{array}{l}\text { SVM based } \\
\text { solution }\end{array}$ & & $\sqrt{ }$ & $\begin{array}{l}\text { Feature } \\
\text { correlation } \\
\text { needs be more } \\
\text { precise. Traffic } \\
\text { generation } \\
\text { and real-time } \\
\text { performance is } \\
\text { missing }\end{array}$ & $\begin{array}{l}\text { use time pattern for } \\
\text { prevention }\end{array}$ & $\begin{array}{l}\text { Ryu } \\
\text { controller } \\
\text { is reduced } \\
\text { by } 36 \% \quad 7 \\
\text { yes }\end{array}$ & yes & \\
\hline $\begin{array}{l}\text { David et al } \\
2019 \text { [112] }\end{array}$ & $\begin{array}{l}\text { Statistical } \\
\text { approach }\end{array}$ & $\sqrt{ }$ & $x$ & $\begin{array}{l}\text { Real time im- } \\
\text { plementation is } \\
\text { missing. }\end{array}$ & $\begin{array}{l}\text { higher detection rate } \\
\text { and accuracy and lesser } \\
\text { processing time }\end{array}$ & $\begin{array}{l}99.6 \% \text { ac- } \\
\text { curacy }\end{array}$ & Yes & Yes \\
\hline $\begin{array}{l}\text { Saxena et } \\
\text { al } 2020 \\
\text { [113] }\end{array}$ & $\begin{array}{l}\text { A third } \\
\text { party } \\
\text { auditor } \\
\text { (TPA)based } \\
\text { packet } \\
\text { traceback } \\
\text { approach }\end{array}$ & $\checkmark$ & $\sqrt{ }$ & $\begin{array}{l}\text { Threshold } \\
\text { value should } \\
\text { vary with } \\
\text { real time } \\
\text { update.But the } \\
\text { value is fixed. }\end{array}$ & $\begin{array}{l}\text { Easy DDoS prevention } \\
\text { in the cloud environ- } \\
\text { ment }\end{array}$ & $\begin{array}{l}97.4 \% \text { ac- } \\
\text { curacy }\end{array}$ & Yes & Yes \\
\hline $\begin{array}{l}\text { Wang et al } \\
2020 \text { [114] }\end{array}$ & $\begin{array}{l}\text { Multilayer } \\
\text { perceptrons }\end{array}$ & $\checkmark$ & $x$ & $\begin{array}{l}\text { If feedback } \\
\text { mechanism } \\
\text { works } \\
\text { incorrectly, } \\
\text { the system } \\
\text { will get wrong } \\
\text { knowledge }\end{array}$ & $\begin{array}{l}\text { correct the detector } \\
\text { when it performed } \\
\text { poorly }\end{array}$ & $\begin{array}{l}\text { Accuracy } \\
92 \%\end{array}$ & Yes & No \\
\hline
\end{tabular}

by adding an ID when a user visits a particular website. Exploiting this ID thereafter, the attacker can determine the visited web pages. Accumulating this sort of information might be helpful to comprehend different user activities including how a user gets to a page, what he likes and so on. This may lead to tie in user behavior to demographics.

Israeli researcher Omer Gil has introduced a method called as deception attack. It has many advantages over cached pages. It mainly targets e-commerce and online payment gateway. This attack occurs on by exploiting cookies. In this attack, user may never find a way to opt out from the trap. A system that is infected by URL poisoning will assign an ID to the victim when he visits the first page. Then, this ID will be a part of the URL without victim's knowledge. All information related to this ID might be recorded as long as he visits the same page. It may also be attached with the browser when a victim visits any original site.

In Fig. 20, attacker intentionally enters ID to the victim's page and stores the number sequence. Further, attacker uses the data for the illegal purpose. Our rigorous exploration in this very topic reveals that no specific research works exist to the solution of this attack.

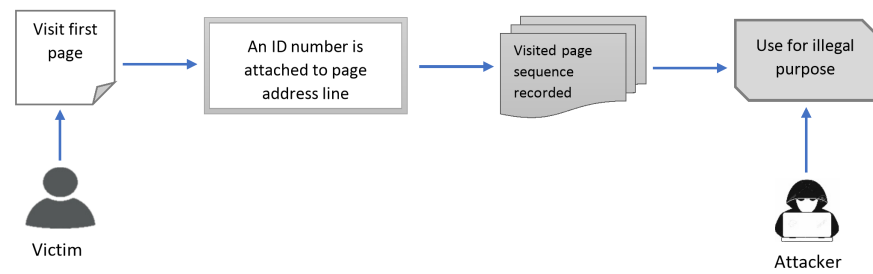

Fig. 20. URL Poisoning Attack: Victim's Visited Page is Recorded using ID Number.

\section{F. Outbound Attack}

A traffic that generates from the insiders is known as outbound traffic [127]. The main reason of locking down outbound attack as securely as inbound is DDoS attack. If an open port is not available to move out traffic, a system network may be immune to this event [128]. Fig. 21] shows a sample scenario of an outbound attack.

Outbound attack can lead to Wild botnet attack that maybe be worst case of this attack.

In this figure, hacker sends traffic to overwhelm the target 
(IJACSA) International Journal of Advanced Computer Science and Applications,

TABLE XIII. STATE-OF-THE-ART SOLUTIONS OF PHISHING

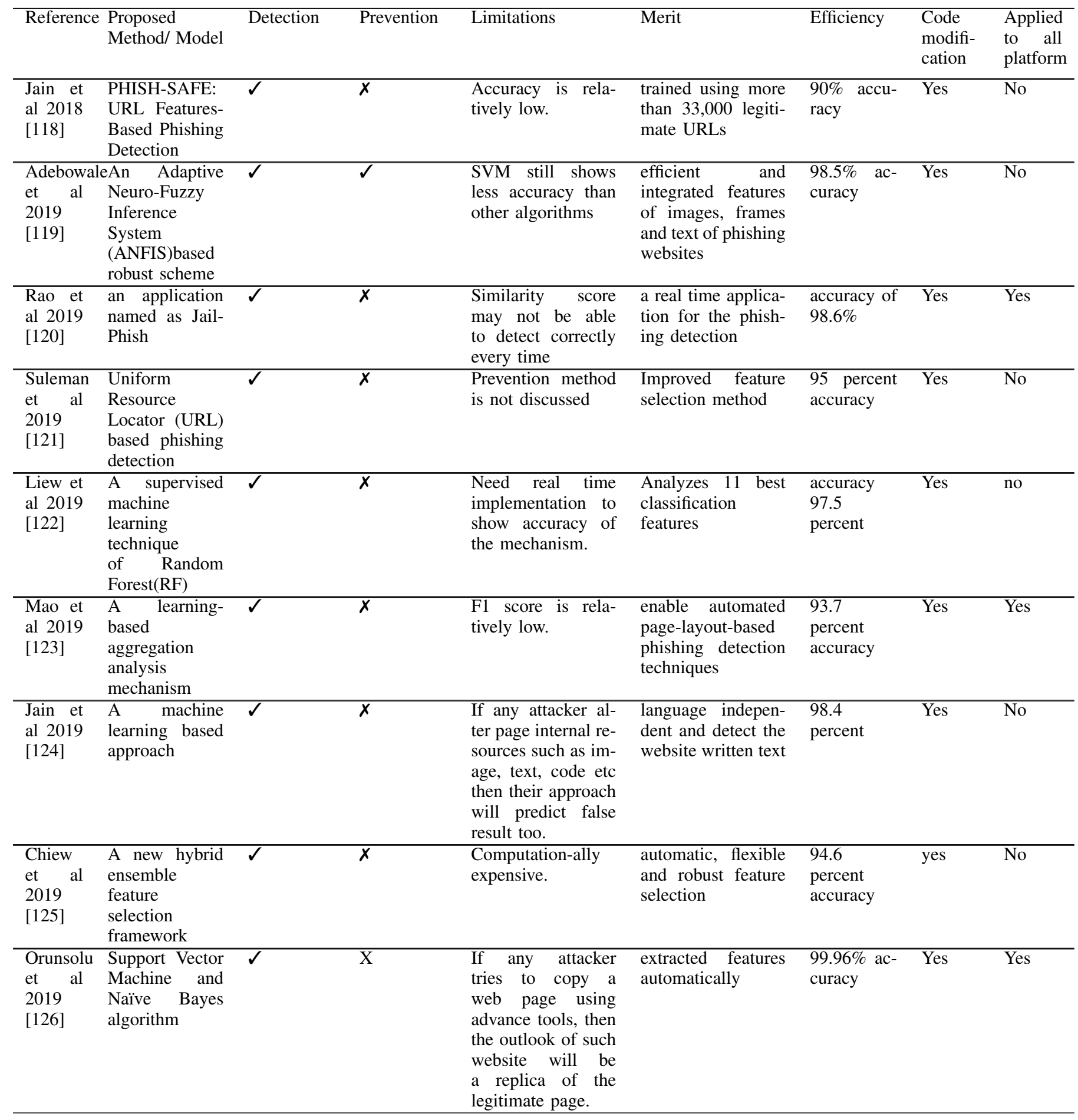

PC. As, he sends payload with the traffic, target may click on this. Once clicked, the server is compromised. Nevertheless, the user also establishes outbound HTTPS connection with the attacker which surely tunnels back and takes control over the system. In most cases, the employee has no idea that they have been compromised, nor does their employer. In such a case, the computer needs to be reinstalled but at least the rest of the network will still be intact. If this connections [128] are restricted to specific protocols and can only be established by the specific users or authenticated users, then the attacks become ineffective.There is no specific research study found on this very topic.

\section{G. Violating Traffic Regulation Conditions Attack}

Traffic regulation [129] means to achieve the required quality of services goals such as bandwidth, load, delay, 


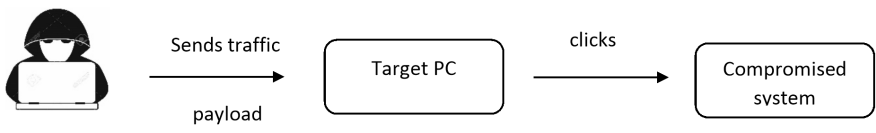

Fig. 21. Outbound Attack: Hacker Sends Payload to Target PC to Comprise the Server.

security etc. Our concern is the issue of security [130]. Policies that relate to traffic regulation might monitor the TCP connections on all IP addresses and ports in a system. IDS traffic regulation (TR) policies for TCP ports limits the total number of connections an application has been active at one time. Attacker may violate the traffic regulation policies by modifying TCP connection of the hosts . It could result in establishing TCP connection by the attacker with the target's host to do malicious activity. After successfully connected with the host, it takes full control over host. To the best of our knowledge, we have not found any significant research endeavors addressing the solutions on this attack.

\section{H. Social Engineering Attack}

Social engineering attack is one of the most popular and easy ways to get any information from any person that may relate to any organization. The attacker designs the process so deceivingly that any person may easily be manipulated. In the context of cyber security, this is used to lure victim to disclose sensitive data, perform security breaches or infect system unknowingly [136].

Shark Tank 2020, Toyota 2019, Cabarrus County 2018, Ethereum Classic 2017, Democratic Party 2016, Ubiquiti Networks, Sony Pictures, Target South Carolina Department of Revenue, RSA. etc. are the most popular social engineering attacks till date.

During the process of conversation, victims are not aware of the intention of the attacker. Therefore, they easily fall in trap. Many types of explicit methods are used to seduce or attract the victim to start a conversation [137]. It may be classified into two types which are, (i) Hunting and (ii) Farming [137].

1) Hunting approach executes the social engineering attack by doing minimum conversation between the target and the hacker. Once hacker is successful in getting the information, he terminates the conversation between them. This process is the most used one in the cyber world. It can encounter a single operand at once [138].

2) Social engineering farming is not something that is practiced often. This is used for some particular situations. To get the information, attacker needs longer period of time to keep himself connected with the user. During this process, the conversation or interaction may change between them. Some cases, target may understand the tactics. If not, then user may get blackmailed by the hacker [138].

In Fig. 22, attacker collects information about the victim and makes a customized attack for the victim. Then, he collects response from the victim and uses the sensitive information against him. The main focus of this attack is to ignore manual

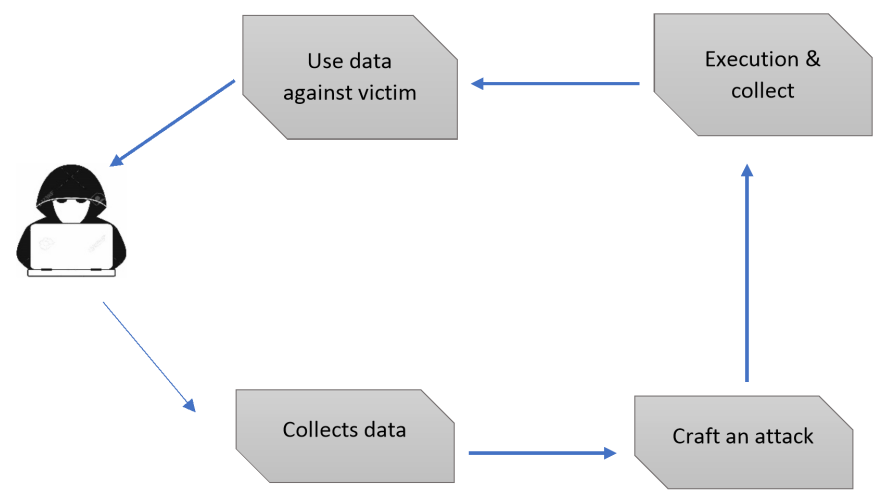

Fig. 22. Social Engineering Attack: Attack Phases.

security process by deceiving user. They may get the weakest link to attack people emotionally [137].

Table XIV lists some existing solutions researched so far.

\section{Malware Attack}

Malware[139] can be a file or software program which is harmful for a system or computer. They may vary from function to function that can do theft, encryption or delete any important data, alter or hijack programs of a system, and monitor any activity of the users without their permissions. Attacker uses ways to spread the malware through physical or virtual means. Some malwares are automatically downloaded to the system as they are designed without the user's knowledge [140]. Some types of malware, that have new techniques, are designed to not only deceive the users but also to detour the anti-virus easily. Anti-sandbox technique can detect malware and delay execution after it leaves the sandbox [141].

Fear has been upgraded its level during the time of corona virus. Many cyber criminals, and ransomware are introduced in this period. Covidlock is one of them[142].

Some types of malware include the following:

1) Virus: A virus is a type of malware that may execute itself without any command and may spread on it's own.

2) Worm: A worm can replicate itself without any host or user program. It spreads itself without human intervention and is directed by malware attackers.

3) Trojan: A trojan virus disguised as legitimate to get access to a system. If it is activated, it starts to follow installations. It can execute their malicious actions by itself.

4) Spyware: Spyware is made to get a collection of information of data on a user device and monitor activity of the victim without their knowledge. It is like keeping an eye on users.

5) Ransomware: Ransomware infects a system, encrypts its data and demands a certain amount of ransom money from the victim in exchange for fixing the system.

6) Rootkit: A rootkit is created by a hacker to get access into the administration level of the target's system. If it is installed, the system gets threat from root or deep infrastructure. 
TABLE XIV. STATE-OF-THE-ART SOLUTIONS OF Social ENGINEERING ATtaCK

\begin{tabular}{|c|c|c|c|c|c|c|c|c|}
\hline Reference & $\begin{array}{l}\text { Proposed } \\
\text { Method/ Model }\end{array}$ & Detection & Prevention & Limitations & Merit & Efficiency & $\begin{array}{l}\text { Code } \\
\text { modifi- } \\
\text { cation }\end{array}$ & $\begin{array}{l}\text { Applied } \\
\text { to all } \\
\text { platform }\end{array}$ \\
\hline $\begin{array}{l}\text { Sawa et al } \\
2016 \text { [131] }\end{array}$ & $\begin{array}{l}\text { Natural } \\
\text { language } \\
\text { processing } \\
\text { techniques }\end{array}$ & $\sqrt{ }$ & $x$ & 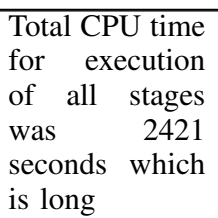 & $\begin{array}{l}\text { applicable to many at- } \\
\text { tack vectors sincerely } \\
\text { on dialog text }\end{array}$ & $\begin{array}{l}\text { Precision } \\
100 \text { percent } \\
\text { and recall } \\
60 \text { percent }\end{array}$ & Yes & No \\
\hline $\begin{array}{l}\text { Abeywardana } \\
\text { et al } 2016 \\
132\end{array}$ & $\begin{array}{l}\text { A layered } \\
\text { defence } \\
\text { strategy SERA }\end{array}$ & $\sqrt{ }$ & $x$ & $\begin{array}{l}\text { Classification } \\
\text { needs more } \\
\text { enhancement. }\end{array}$ & $\begin{array}{l}\text { Detailed information of } \\
\text { attacks }\end{array}$ & $\begin{array}{l}\text { Not } \\
\text { mentioned }\end{array}$ & No & No \\
\hline $\begin{array}{l}\text { Dan et al } \\
2019[133\end{array}$ & $\begin{array}{l}\text { Data Protection } \\
\text { Mode }\end{array}$ & $\sqrt{ }$ & $\sqrt{ }$ & $\begin{array}{lr}\text { Attack ratio } \\
\text { is still high } \\
\text { enough to } \\
\text { harm the } \\
\text { organization. }\end{array}$ & $\begin{array}{l}\text { Modular design, More } \\
\text { state transitions and In- } \\
\text { corporates and imple- } \\
\text { ments the data protec- } \\
\text { tion process }\end{array}$ & $\begin{array}{l}\text { Not } \\
\text { mentioned }\end{array}$ & Yes & Yes \\
\hline $\begin{array}{l}\text { Lansley et } \\
\text { al } 2019 \\
{[134}\end{array}$ & $\begin{array}{l}\text { A two-stage } \\
\text { approach that } \\
\text { detects social } \\
\text { engineering } \\
\text { attacks } \\
\text { and based } \\
\text { on natural } \\
\text { language } \\
\text { processing }\end{array}$ & $\sqrt{ }$ & $\bar{x}$ & $\begin{array}{l}\text { More algorithm } \\
\text { needed to eval- } \\
\text { uate the pro- } \\
\text { gram for com- } \\
\text { parison. }\end{array}$ & $\begin{array}{l}\text { evaluated using both } \\
\text { real and semi-synthetic } \\
\text { conversation points }\end{array}$ & $\begin{array}{l}\text { accuracy } \\
0.917\end{array}$ & Yes & Yes \\
\hline $\begin{array}{l}\text { Mouton } \\
\text { et al } 2019 \\
{[135}\end{array}$ & SEADM & $\sqrt{ }$ & $\bar{x}$ & $\begin{array}{l}\text { The method is } \\
\text { not adhered to } \\
\text { every request. }\end{array}$ & $\begin{array}{l}\text { Explored social engi- } \\
\text { neering as a domain }\end{array}$ & $\begin{array}{l}\text { Not } \\
\text { mentioned }\end{array}$ & yes & Yes \\
\hline
\end{tabular}

7) Backdoor: A backdoor is a form of virus or remote access Trojan. It constructs a backdoor into a compromised system that facilitates the attacker for remote access without causing any disturbance of user's security issues.

8) Adware: The main purpose of the adware is to trail the browsing history of a user with the intention of displaying advertisements. This allures an user to make any purchase.

9) Keylogger: Keylogger is a type of monitoring system which nearly sees everything that users actually do on the computers including emails, web pages etc.

State-of-the-art research works on malware attack are depicted in Table XV

\section{J. IoT Botnet Attack}

A group of computers, appliances and connected devices [149] [150] that have been controlled by a hacker or a hacker group for illegitimate purpose is known as IoT botnet. It is made up of computers that can be accessed remotely by a hacker without the victim's knowledge. It forwards the data to the other computers through internet. Botnets are increasing and have become more advanced since the evolution of IoT. It may target many devices and appliances on any infrastructure and inject them with malicious payloads or packets. The evolution of IoT increases the risk of security breaches [151][152].

In Fig. 23. The IoT is comprised of diverge devices including cameras, routers, DVRs, wearable and other embedded technologies.
Three botnets have been occurred in 2018. It gave rise to different domains, but all of them are inter connected. Each of them are skillful and ingenious system which can detect fraud. Google, White Ops, and other tech companies came together at that time to invade the operation of this attack.

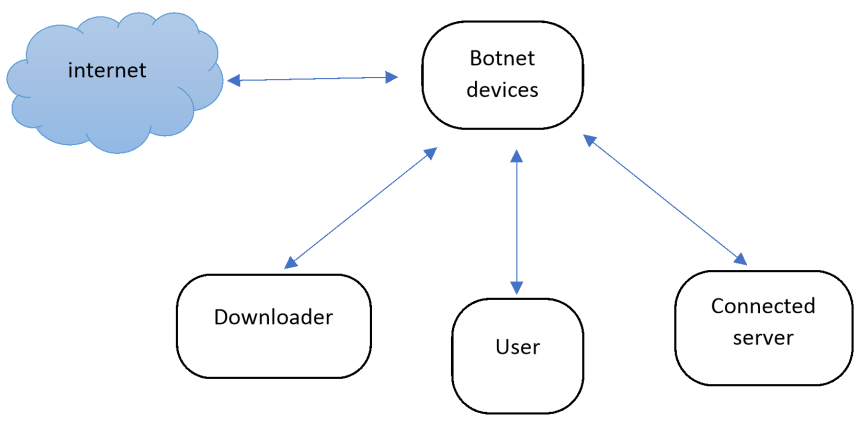

Fig. 23. Connected IoT Devices: Botnet Devices are Connected to Every Possible Device Through Internet.

As most of the devices are Linux and Unix based, they become the common target of the attacker. Since in those system, an executable format exists which is modifiable by the attacker. The modified file becomes the malware that targets SSH or telnet network protocols. Once the system is compromised, the payload is delivered to the system through installation and thus turned into a botnet. [153][154]. Some existing solutions related to this attack is summarized in Table XVI. 
(IJACSA) International Journal of Advanced Computer Science and Applications,

Vol. 12, No. 8, 2021

TABLE XV. STATE-OF-THE-ARt Solutions of Malware AtTack

\begin{tabular}{|c|c|c|c|c|c|c|c|c|}
\hline Reference & $\begin{array}{l}\text { Proposed } \\
\text { Method/ Model }\end{array}$ & Detection & Prevention & Limitations & Merit & Efficiency & $\begin{array}{l}\text { Code } \\
\text { modifi- } \\
\text { cation }\end{array}$ & $\begin{array}{l}\text { Applied } \\
\text { to all } \\
\text { platform }\end{array}$ \\
\hline 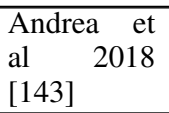 & MADAM & $\sqrt{ }$ & $\sqrt{ }$ & $\begin{array}{l}\text { Performance } \\
\text { measurement is } \\
\text { missing }\end{array}$ & $\begin{array}{l}\text { developed a binary } \\
\text { rewriting tool }\end{array}$ & $\begin{array}{l}\text { Not } \\
\text { mentioned }\end{array}$ & Yes & Yes \\
\hline $\begin{array}{l}\text { Mishra et al } \\
2019 \text { [144 }\end{array}$ & VMANALYZER & $\sqrt{ }$ & $x$ & $\begin{array}{l}\text { Imbalanced } \\
\text { dataset which } \\
\text { leads to } \\
\text { uncertainty } \\
\text { in the normal } \\
\text { traces of } \\
\text { processes. }\end{array}$ & $\begin{array}{l}\text { feature vector is build } \\
\text { for each process in } \\
\text { monitored TVM }\end{array}$ & $\begin{array}{l}4.7-100 \\
\text { percent } \\
\text { accuracy }\end{array}$ & Yes & yes \\
\hline $\begin{array}{l}\text { Maiorca } \\
\text { et al } 2019 \\
\text { [145] }\end{array}$ & $\begin{array}{l}\text { Command- } \\
\text { and-control } \\
\text { botnets }\end{array}$ & $\sqrt{ }$ & $x$ & $\begin{array}{lr}\begin{array}{l}\text { Details } \\
\text { methods }\end{array} & \text { of } \\
\text { missing. } & \\
\end{array}$ & $\begin{array}{l}\text { categorize known vul- } \\
\text { nerabilities of learning- } \\
\text { based PDF malware }\end{array}$ & $\begin{array}{l}\text { Not } \\
\text { mentioned }\end{array}$ & Yes & No \\
\hline $\begin{array}{l}\text { Gan et al } \\
2020 \text { [146 }\end{array}$ & $\begin{array}{l}\text { A dynamical } \\
\text { propagation } \\
\text { model }\end{array}$ & $x$ & $\sqrt{ }$ & $\begin{array}{l}\text { Adjusting sys- } \\
\text { tem parameter } \\
\text { is difficult. }\end{array}$ & $\begin{array}{l}\text { discussed behavior of } \\
\text { malware under an in- } \\
\text { fected cloud environ- } \\
\text { ment }\end{array}$ & $\begin{array}{l}\text { Not } \\
\text { mentioned }\end{array}$ & Yes & Yes \\
\hline $\begin{array}{l}\text { Alazab et al } \\
2020 \text { [147] }\end{array}$ & $\begin{array}{l}\text { An automated } \\
\text { process by } \\
\text { using a scoring } \\
\text { and grouping } \\
\text { technique }\end{array}$ & $\sqrt{ }$ & $x$ & $\begin{array}{l}\text { Use of more } \\
\text { machine } \\
\text { learning } \\
\text { algorithms } \\
\text { may achieve } \\
\text { more accurate } \\
\text { results. }\end{array}$ & $\begin{array}{l}\text { assist in the process } \\
\text { of malware forensic in- } \\
\text { vestigation }\end{array}$ & $\begin{array}{l}94.3 \\
\text { percent } \\
\text { accuracy }\end{array}$ & Yes & No \\
\hline $\begin{array}{l}\text { Mishra et al } \\
2020[148]\end{array}$ & KVMInspector & $\sqrt{ }$ & $x$ & $\begin{array}{l}\text { It is not in- } \\
\text { corporated with } \\
\text { network moni- } \\
\text { toring function- } \\
\text { alities }\end{array}$ & $\begin{array}{lr}\text { Considered } & \text { as } \\
\text { advanced } & \text { security } \\
\text { check } & \end{array}$ & $\begin{array}{l}81.25 \%- \\
99.92 \%(\mathrm{UNM}) \\
\text { and } \\
95.43 \% 0- \\
97.81 \% \text { (Elog) }\end{array}$ & Yes & yes \\
\hline
\end{tabular}

\section{Intrusion and Extrusion Events: A Big Picture}

In this section, we have recapitulated all the intrusion and extrusion events by means of their types, how and where they occur, consequences and existing solutions, as presented in Table XVII. 
TABLE XVI. State-OF-THE-ARt SOLUTIONS OF IoT BotNet ATtack

\begin{tabular}{|c|c|c|c|c|c|c|c|c|}
\hline Reference & $\begin{array}{l}\text { Proposed } \\
\text { Method/ Model }\end{array}$ & Detection & Prevention & Limitations & Merit & Efficiency & $\begin{array}{l}\text { Code } \\
\text { modifi- } \\
\text { cation }\end{array}$ & $\begin{array}{l}\text { Applied } \\
\text { to all } \\
\text { platform }\end{array}$ \\
\hline $\begin{array}{l}\text { Meidan et } \\
\text { al } 2018 \\
{[14}\end{array}$ & N-BaIoT & $\sqrt{ }$ & $\bar{x}$ & $\begin{array}{l}\text { Connection } \\
\text { between IoT } \\
\text { devices that has } \\
\text { low prediction } \\
\text { rate in their } \\
\text { network is not } \\
\text { allowed due } \\
\text { to security } \\
\text { polices. }\end{array}$ & $\begin{array}{l}\text { Create } \\
\text { experimantal } \\
\text { setup for } \\
\text { dataset }\end{array}$ & .0007 FPR & Yes & Yes \\
\hline $\begin{array}{l}\text { Tzagkarakis } \\
\text { et al } 2019 \\
{[155]}\end{array}$ & $\begin{array}{l}\text { Sparsity } \\
\text { representation } \\
\text { framework }\end{array}$ & $\sqrt{ }$ & $\bar{x}$ & $\begin{array}{l}\text { The decision } \\
\text { threshold is } \\
\text { estimated } \\
\text { using only } \\
\text { begin training } \\
\text { instances. }\end{array}$ & $\begin{array}{l}\text { Lightweight } \\
\text { method }\end{array}$ & $\begin{array}{l}\text { Not } \\
\text { mentioned }\end{array}$ & Yes & No \\
\hline $\begin{array}{l}\text { Banerjee } \\
\text { et al } 2019 \\
{[156]}\end{array}$ & Honeynet & $\sqrt{ }$ & $\bar{x}$ & $\begin{array}{l}\text { Malicious bina- } \\
\text { ries, attack re- } \\
\text { plays are not } \\
\text { considered. }\end{array}$ & $\begin{array}{l}\text { provides } \\
\text { activity logs of } \\
\text { the intrusion } \\
\text { attempt }\end{array}$ & $\begin{array}{l}100 \text { percent } \\
\text { accuracy }\end{array}$ & yes & No \\
\hline $\begin{array}{l}\text { Dange et al } \\
2020 \text { [157] }\end{array}$ & $\begin{array}{l}\text { CNN-based } \\
\text { deep learning } \\
\text { model }\end{array}$ & $\sqrt{ }$ & $x$ & $\begin{array}{l}\text { There is a } \\
\text { difference } \\
\text { in power } \\
\text { consumption } \\
\text { as it negotiates } \\
\text { the condition } \\
\text { of various WiFi } \\
\text { signal. }\end{array}$ & $\begin{array}{l}\text { details of IoT } \\
\text { attacks }\end{array}$ & $\begin{array}{l}\text { Not } \\
\text { mentioned }\end{array}$ & Yes & No \\
\hline
\end{tabular}


TABLE XVII. SUMMARY OF INTRUSION AND EXTRUSION EVENTS

\begin{tabular}{|c|c|c|c|c|c|c|}
\hline Attack name & Type & How it occurs & Where it occurs & Consequences & Existing methods/ models & Complexity \\
\hline $\begin{array}{l}\mathrm{TCP} \quad \mathrm{ACK} \\
\text { storm attack }\end{array}$ & intrusion & $\begin{array}{l}\text { It can exploits a } \\
\text { design architecture } \\
\text { in the TCP } \\
\text { specifications }\end{array}$ & Application layer & $\begin{array}{l}\text { Effect the web- } \\
\text { sites regular work } \\
\text { by sending lots of } \\
\text { traffic }\end{array}$ & $\begin{array}{l}\text { Modifying the TCP ,State tran- } \\
\text { sition model, hypervisor at } \\
\text { close state, FMVEA and mul- } \\
\text { tiset semantic, MLPNN struc- } \\
\text { ture }\end{array}$ & Low \\
\hline $\begin{array}{l}\text { Fraggle } \\
\text { attack }\end{array}$ & Intrusion & $\begin{array}{l}\text { Dispatches numerous } \\
\text { numbers of malicious } \\
\text { traffic to overwhelm a } \\
\text { router's transmittable } \\
\text { address in the net- } \\
\text { work }\end{array}$ & Transport layer & $\begin{array}{l}\text { Cripple any } \\
\text { servers for hours, } \\
\text { or even days }\end{array}$ & SACL filtering method & Low \\
\hline $\begin{array}{l}\text { An ICMP } \\
\text { redirect } \\
\text { message } \\
\text { attack }\end{array}$ & Intrusion & $\begin{array}{l}\text { A message is de- } \\
\text { signed for informing } \\
\text { a host that there is a } \\
\text { more optimal route is } \\
\text { available so that user } \\
\text { may redirect to the } \\
\text { malicious traffic sys- } \\
\text { tem. }\end{array}$ & Transport layer & $\begin{array}{l}\text { Cause problems } \\
\text { in fire-walled } \\
\text { environments } \\
\text { where flow traffic } \\
\text { patterns are non- } \\
\text { deterministic }\end{array}$ & $\begin{array}{l}\text { BigFlow Open Flow, PrECast } \\
\text { proxy service, AR-match tech- } \\
\text { nique, Signature based and } \\
\text { Machine learning tool, Cen- } \\
\text { tralized system }\end{array}$ & Low \\
\hline $\begin{array}{l}\text { Internet } \\
\text { protocol } \\
\text { fragment } \\
\text { attack }\end{array}$ & Intrusion & $\begin{array}{l}\text { Attacker uses the } \\
\text { fragmentation } \\
\text { protocol within } \\
\text { IP to attack the } \\
\text { system. }\end{array}$ & Transport layer & $\begin{array}{l}\text { System may } \\
\text { freeze or } \\
\text { overwhelmed } \\
\text { because of the } \\
\text { attack }\end{array}$ & $\begin{array}{l}\text { BGP Flowspec rules, } \\
\text { Edwards-curve Digital Signa- } \\
\text { ture Algorithm, Sparsely- } \\
\text { Tagged Fragmentation } \\
\text { Marking approach, SecuPAN } \\
\text { proposed tool, Integrated IP } \\
\text { Source Address Validation } \\
\text { Architecture (ISAVA) }\end{array}$ & High \\
\hline $\begin{array}{l}\text { Perpetual } \\
\text { echo attack }\end{array}$ & Intrusion & $\begin{array}{l}\text { Any illegitimate ac- } \\
\text { tivity happens at port } \\
7 \text { in the form of } \\
\text { spoofing any system } \\
\text { knows as perpetual at- } \\
\text { tack. }\end{array}$ & Transport layer & $\begin{array}{l}\text { Large amount of } \\
\text { network traffic } \\
\text { causes delay. }\end{array}$ & $\begin{array}{lr}\text { Prey Predator } & (\mathrm{PP}), \quad \text { Ant } \\
\text { Colony } & \text { Optimization, } \\
\text { Modified } & \text { protocol } \\
\text { specifications } & \end{array}$ & Low \\
\hline $\begin{array}{l}\text { Internet } \\
\text { Control } \\
\text { Message } \\
\text { Protocol } \\
\text { (ICMP) } \\
\text { tunneling } \\
\text { attack }\end{array}$ & Intrusion & $\begin{array}{l}\text { Attacker inserts ma- } \\
\text { licious data by using } \\
\text { ICMP tunneling and } \\
\text { echo the packet to re- } \\
\text { mote computer }\end{array}$ & Network layer & $\begin{array}{l}\text { Any sensitive } \\
\text { data or access } \\
\text { in private sector } \\
\text { may done by this } \\
\text { attack. }\end{array}$ & $\begin{array}{l}\text { A novel mechanism of } 5 \text { al- } \\
\text { gorithms, Covert Channel De- } \\
\text { tection using Support Vector } \\
\text { Machine, Stateless and moni- } \\
\text { toring model, Stateless model }\end{array}$ & High \\
\hline Smurf attack & Intrusion & $\begin{array}{l}\text { The attacker creates } \\
\text { a malicious network } \\
\text { packets attached to a } \\
\text { IP and send it to the } \\
\text { victim's system }\end{array}$ & Network layer & $\begin{array}{l}\text { It can freeze } \\
\text { company servers } \\
\text { for days and } \\
\text { months. Data } \\
\text { loss can happen }\end{array}$ & $\begin{array}{l}\text { SDN based technique, an en- } \\
\text { hanced History-based IP Fil- } \\
\text { tering scheme, Pattern Match- } \\
\text { ing Techniques, principal com- } \\
\text { ponent analysis }\end{array}$ & High \\
\hline $\begin{array}{l}\text { Router } \\
\text { attack }\end{array}$ & Intrusion & $\begin{array}{l}\text { Injecting vulnerabili- } \\
\text { ties to the router }\end{array}$ & Network layer & $\begin{array}{l}\text { Attacks impact } \\
\text { network services } \\
\text { and business } \\
\text { operations } \\
\text { distributed } \\
\text { router shadow, } \\
\text { an Interest } \\
\text { flow balancing } \\
\text { method, Run- } \\
\text { time protector } \\
\text { and Restart-time } \\
\text { protector. }\end{array}$ & $\begin{array}{l}\text { Distributed router } \\
\text { an Interest flow balancing } \\
\text { method, Run-time protector } \\
\text { and Restart-time protector, } \\
\text { Pushback method, Scalable } \\
\text { Method }\end{array}$ & Low \\
\hline $\begin{array}{l}\text { Slow and } \\
\text { fast port } \\
\text { scan attack }\end{array}$ & Intrusion & $\begin{array}{l}\text { May blend into the } \\
\text { network noise never } \\
\text { exceeding detection } \\
\text { thresholds and } \\
\text { exhausting detection } \\
\text { system state }\end{array}$ & Network layer & $\begin{array}{l}\text { Creates changes } \\
\text { in the normalcy } \\
\text { of the traffic }\end{array}$ & \begin{tabular}{lrr} 
Distributed router & \multicolumn{1}{c}{ shadow, } \\
an Interest flow balancing \\
method, Run-time protector \\
and Restart-time protector, \\
Pushback method, Scalable \\
Method, Exposure map, \\
Distributed \\
Model, Cooperative \\
Scan Chain Encryption, \\
Classification algorithm, \\
time-aware metrics in NIDS \\
evaluations, Fuzzy Rule \\
Interpolation
\end{tabular} & High \\
\hline
\end{tabular}




\begin{tabular}{|c|c|c|c|c|c|c|}
\hline Attack name & type & How it occurs & Where it occurs & Consequences & Existing methods/ models & complexity \\
\hline $\begin{array}{l}\text { Restricted IP } \\
\text { attack }\end{array}$ & Intrusion & $\begin{array}{l}\text { Attacker restricted the } \\
\text { access to the particu- } \\
\text { lar site and defined set } \\
\text { of IP address }\end{array}$ & Network layer & $\begin{array}{ll}\text { Restrict } & \text { user's } \\
\text { website } & \end{array}$ & $\begin{array}{l}\text { ARP table update state-based } \\
\text { detection approach, SQL } \\
\text { Injection detection mechanism } \\
\text { An adaptive framework, } \\
\text { Packet filtration, payload } \\
\text { distribution model, generic } \\
\text { authorization framework }\end{array}$ & Low \\
\hline ARP attack & Intrusion & $\begin{array}{l}\text { When a hacker } \\
\text { dispatches false ARP } \\
\text { messages to the local } \\
\text { network and connect } \\
\text { it with the system. }\end{array}$ & Data link layer & $\begin{array}{l}\text { Hackers can } \\
\text { steal sensitive } \\
\text { information from } \\
\text { the targeted } \\
\text { computers. }\end{array}$ & $\begin{array}{l}\text { Discrete event system, } \\
\text { IP probing, ARP table, } \\
\text { ARP filtering, Centralized } \\
\text { methodology (central server), } \\
\text { Novel mechanism, Secondary } \\
\text { ARP table etc. }\end{array}$ & Low \\
\hline $\begin{array}{l}\text { Ping of death } \\
\text { attack }\end{array}$ & Intrusion & $\begin{array}{l}\text { Attacker sends mali- } \\
\text { cious ping to a system } \\
\text { to flood the system. }\end{array}$ & Data link layer & $\begin{array}{l}\text { It can crash, } \\
\text { damage or freeze } \\
\text { the victim's } \\
\text { computer } \\
\text { by sending } \\
\text { oversized } \\
\text { malformed } \\
\text { packet }\end{array}$ & No specific solution & low \\
\hline $\begin{array}{l}\text { SYN floods } \\
\text { attack }\end{array}$ & Intrusion & $\begin{array}{l}\text { Connected with syn } \\
\text { false packet and } \\
\text { TCP connection } \\
\text { established }\end{array}$ & Data link layer & $\begin{array}{l}\text { Attacker makes } \\
\text { the system } \\
\text { unavailable for } \\
\text { the user by } \\
\text { flooding with } \\
\text { legitimate traffic. }\end{array}$ & $\begin{array}{l}\text { GT-IDS-DJ Method, Three } \\
\text { Way Counter Algorithm for } \\
\text { Attack Detection, system } \\
\text { architecture for efficient } \\
\text { detection, The Adaptive } \\
\text { threshold algorithm and the } \\
\text { cumulative sum (CUSUM), } \\
\text { DDoS Cyber-Shelter model, } \\
\text { three modules, such as sniffer } \\
\text { module, analysis module and } \\
\text { active defense module, AR } \\
\text { modeling, SYN Flood Attack } \\
\text { Detection Based on Bayes } \\
\text { Estimator (SFADBE), SSP-a } \\
\text { coordination of the SDN } \\
\text { Open-flow switch }\end{array}$ & Low \\
\hline $\begin{array}{l}\text { Malformed } \\
\text { attack }\end{array}$ & Intrusion & $\begin{array}{l}\text { Incorrectly formed IP } \\
\text { packets are formed } \\
\text { and sent to the victim } \\
\text { to crash the system }\end{array}$ & Data link layer & $\begin{array}{l}\text { The system of the } \\
\text { victim may get } \\
\text { confuse and gets } \\
\text { crashed }\end{array}$ & $\begin{array}{l}\text { TCP trace module, Threshold } \\
\text { value set for detect malformed } \\
\text { packet, Generates ACL }\end{array}$ & Low \\
\hline $\begin{array}{l}\text { Supply chain } \\
\text { attack }\end{array}$ & Extrusion & 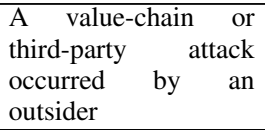 & Application layer & $\begin{array}{l}\text { Causes major } \\
\text { data breach }\end{array}$ & No solution yet & High \\
\hline $\begin{array}{l}\text { DeOS } \\
\text { (destruction } \\
\text { of services) } \\
\text { attack }\end{array}$ & Extrusion & $\begin{array}{l}\text { Targets an organiza- } \\
\text { tion's entire online } \\
\text { presence as well as } \\
\text { their ability to recover } \\
\text { from the attack after- } \\
\text { wards }\end{array}$ & Application layer & $\begin{array}{l}\text { Could } \\
\text { businesses } \\
\text { in a position } \\
\text { where they } \\
\text { have to rebuild } \\
\text { infrastructure } \\
\text { from scratch } \\
\text { or pay a high } \\
\text { ransom to the } \\
\text { attackers }\end{array}$ & No solution yet & High \\
\hline $\begin{array}{l}\text { Distributed } \\
\text { denial of } \\
\text { services } \\
\text { (DDOS) } \\
\text { Attack }\end{array}$ & Extrusion & $\begin{array}{l}\text { Malicious attempt to } \\
\text { make an online ser- } \\
\text { vice unavailable to } \\
\text { users }\end{array}$ & Application layer & $\begin{array}{l}\text { Make any } \\
\text { website } \\
\text { or } \quad \text { system } \\
\text { and servers } \\
\text { unavailable to } \\
\text { legitimate users }\end{array}$ & $\begin{array}{l}\text { Graphic model, central con- } \\
\text { trol of SDN, Artificial Neu- } \\
\text { ral Network (ANN) algorithm } \\
\text { Umbrella, SVM based so- } \\
\text { lution, statistical approach, a } \\
\text { third party auditor (TPA)based } \\
\text { packet traceback approach, } \\
\text { An Unsupervised Approach, } \\
\text { multilayer perceptrons }\end{array}$ & Low \\
\hline
\end{tabular}


(IJACSA) International Journal of Advanced Computer Science and Applications,

Vol. 12, No. 8, 2021

\begin{tabular}{|c|c|c|c|c|c|c|}
\hline Attack name & type & How it occurs & Where it occurs & Consequences & Existing methods/ models & complexity \\
\hline $\begin{array}{l}\text { Phishing at- } \\
\text { tack }\end{array}$ & Extrusion & $\begin{array}{l}\text { Targets are contacted } \\
\text { via email,text or link } \\
\text { disguised as legiti- } \\
\text { mate institution }\end{array}$ & Application layer & $\begin{array}{l}\text { Steals Sensitive } \\
\text { information }\end{array}$ & $\begin{array}{l}\text { An Adaptive } \\
\text { Fuzzy Inference System } \\
\text { (ANFIS), Jail-Phish, URL- } \\
\text { based detection system, } \\
\text { light-weight deep learning } \\
\text { algorithm, Uniform Resource } \\
\text { Locator (URL) based method, } \\
\text { supervised technique of } \\
\text { Random Forest(RF), learning- } \\
\text { based aggregation analysis } \\
\text { mechanism, Machine Learning } \\
\text { techniques and algorithms etc. }\end{array}$ & High \\
\hline $\begin{array}{l}\text { URL poison- } \\
\text { ing attack }\end{array}$ & Extrusion & $\begin{array}{l}\text { Track the identifica- } \\
\text { tion number added by } \\
\text { the attacker in the } \\
\text { web browser and gets } \\
\text { information from that } \\
\text { victim when he/she } \\
\text { visits the particular } \\
\text { site }\end{array}$ & Transport layer & $\begin{array}{l}\text { Tracks user to get } \\
\text { desired informa- } \\
\text { tion }\end{array}$ & No specific solution yet & High \\
\hline $\begin{array}{l}\text { Outbound at- } \\
\text { tack }\end{array}$ & Extrusion & $\begin{array}{l}\text { Attacker tunnels back } \\
\text { in over that connec- } \\
\text { tion to take control of } \\
\text { the employees' com- } \\
\text { puter }\end{array}$ & Network layer & $\begin{array}{l}\text { Unlimited email } \\
\text { or file transfers } \\
\text { might let the at- } \\
\text { tacker enter into } \\
\text { the network and } \\
\text { get sensitive in- } \\
\text { formation outside }\end{array}$ & No specific solution yet & Low \\
\hline $\begin{array}{l}\text { Violating } \\
\text { Traffic } \\
\text { regulation } \\
\text { conditions } \\
\text { attack }\end{array}$ & Extrusion & $\begin{array}{l}\text { Violating traffic regu- } \\
\text { lations }\end{array}$ & Network layer & $\begin{array}{l}\text { Causes any } \\
\text { discontinuity } \\
\text { to the network } \\
\text { normal behavior }\end{array}$ & No solutions yet & Low \\
\hline $\begin{array}{l}\text { Social } \\
\text { engineering } \\
\text { attack }\end{array}$ & Extrusion & $\begin{array}{l}\text { Gather information } \\
\text { about someone } \\
\text { by exploiting human } \\
\text { weakness that inherits } \\
\text { every organization }\end{array}$ & Network layer & $\begin{array}{l}\text { Can control one } \\
\text { life through vir- } \\
\text { tual manipulating }\end{array}$ & $\begin{array}{l}\text { Data Protection Mode, two- } \\
\text { stage approach that detects } \\
\text { social engineering attacks } \\
\text { and based on natural language } \\
\text { processing, SEADM, CANDY, } \\
\text { SMS-based second factor } \\
\text { authentication, multi-layered } \\
\text { shield, natural language } \\
\text { processing techniques, layered } \\
\text { defence strategy SERA }\end{array}$ & High \\
\hline Malware & Extrusion & $\begin{array}{l}\text { Any program or file } \\
\text { that is harmful in- } \\
\text { jected through any } \\
\text { way in the system }\end{array}$ & Data link layer & $\begin{array}{l}\text { It } r \text { thefts, } \\
\text { encrypts, or } \\
\text { deletes the data. } \\
\text { It can spy on } \\
\text { computer activity } \\
\text { without user } \\
\text { knowledge or } \\
\text { permission }\end{array}$ & $\begin{array}{l}\text { A dynamical propagation } \\
\text { model, an automated } \\
\text { method by using a } \\
\text { scoring and grouping } \\
\text { technique, KVMInspector, } \\
\text { VMANALYZER, command- } \\
\text { and-control botnets etc }\end{array}$ & High \\
\hline IoT botnet & Extrusion & $\begin{array}{l}\text { It is accessed from } \\
\text { a remote computer } \\
\text { without the owners' } \\
\text { knowledge and set } \\
\text { forward transmissions } \\
\text { to other computers on } \\
\text { the Internet }\end{array}$ & Physical layer & $\begin{array}{lr}\text { It } & \text { causes } \\
\text { breaches } & \text { to } \\
\text { all related } & \text { IoT } \\
\text { devices } & \end{array}$ & $\begin{array}{lr}\text { N-BaIoT, } & \text { IoT-BAI } \\
\text { model, CNN-based } \text { deep } \\
\text { learning, MOPSO, sparsity } \\
\text { representation framework, } \\
\text { Honeynet }\end{array}$ & High \\
\hline \multicolumn{7}{|c|}{ End of Table } \\
\hline
\end{tabular}




\section{Open Challenges and Future Research Issues}

Theoretically, it is expected from computer security mechanisms to prevent attacks and to provide solutions to the threats. If not impossible, it should be capable of predicting future threats. As a consequence, towards fulfilling this expectation, researchers around the globe are working to design, develop and implement increasingly secure systems.

Our effort of excavating numerous research papers conveys what aspects of intrusion and extrusion have been studied and what have not. What concerns us the most is that there is no unified policy or mechanism exists that could be applied to an enterprise system to tackle the possible intrusion or extrusion events. We strongly believe that there is a need for a smart system that might learn and take effective countermeasures against the impending threats. Therefore, we would like to make suggestions for future directions to the research community.

One of the challenges is to build new data sets. Due to the rapid advancement of technology, innovative attack methods also evolve. Protocol developed using existing old data sets do not reflect the impending innovative threats to be mitigated or neutralize. As a natural consequence, research on this very issue requires tremendous attention.

With the advent of deep learning technique, security research got new research dimension. However, one of the limitations of using this in security, particularly in intrusion detection, is to balance between high accuracy and minimal false alarms. This limitation mainly presents in the Convolution neural networks (CNN). Also, using Feed-forward neural networks (FNN) for multi-class classification is a limiting factor. The third limitation includes performance degradation in IDS under heavy traffic load. Furthermore, using Deep Neural Network (DNN) causes higher execution time due to the larger training dataset. However, developing new methods using deep learning, if not impossible, might mitigate the mentioned limitations.

One of the important concerns regarding present research endeavors is that researchers apply variations of machine learning, if results are convincing, they conclude their methods may be applicable for certain scenarios. However, we argue that an interpretable or explainable reasons should be there is to why certain machine learning methods work better.

Software defined network (SDN) mingled with machine learning approaches is the new trends in IDS. However, SDN itself might be the interest to the attacker. This obviates to excavate the vulnerabilities in SDN. On a different note, since SDN network controller suffers from performance degradation for larger network, new research efforts are essential to address the challenge.

We believe that each attack is unique and attackers are very intelligent. Irrespective of the nature and severity of attacks, the future research on this domain should consider not only the detection and prevention of existing attacks but also should predict the future threats. If not impossible, if that is achieved to a certain extent, research community may render meaningful and fruitful contributions to the society.

The difficulties that lay ahead of us in infiltration and extrusion detection systems have grown significantly in recent years. The following is a list of them.

- Inability to decrease the amount of false positives, reducing IDS efficiency. A good IDS should have a high level of accuracy and recall, as well as a low rate of false positives and false negatives. A key concern is how one can have faith in the outcome.

- The amount of time it takes to analyze such a vast amount of data for training is enormous.

- In IDS, improving classification accuracy is a significant goal. It forces to concentrate on a multi-classifier system.

- Due to a lack of computer resources and a significant increase in targeted assaults, a real-time intrusion detection system is urgently required. However, putting it into practice in a real-world setting is difficult.

- A problem is the lack of a common assessment dataset that can mimic real-time IDS.

- Many research employ the selection of functions to reduce the computer complexity in function reduction work. To carry out the data deduction task, greater focus is necessary.

- A combination detection and anomaly detection approach is necessary.

It's not an amazing mountain to create an effective detecting system. The above mentioned difficulties might greatly contribute to this trip.

\section{CONCLUSION}

Network attacks are a daily security concern that may be mitigated. As a result, it is critical to explore more complicated security alternatives than simple firewall systems today. This article discusses numerous forms of attacks on TCP/IP networks at each layer, the merits and limits of Intrusion Detection System (IDS) and Extrusion Detection System (EDS) solutions, IDS and EDS efficiency and code environment, and utilized techniques for both.Some intrusion detection systems have progressed significantly, and the data generated by software and the tactics used by attackers are getting increasingly sophisticated. This makes it difficult to discern between genuine system use and potential infiltration. A false alarm, also known as a false positive, occurs when an IDS erroneously detects an activity as a probable intrusion.Poorly designed intrusion detection systems, particularly behavior-based intrusion detection systems, can generate a large number of false positives. In the case of passiveresponse intrusion detection systems, this might result in an overwhelming administrative load (getting paged for a false alarm every 3 minutes becomes annoying very quickly). In the case of active-response IDS, this might potentially result in a DoS situation.If the IDS incorrectly blocks a valid user's IP address. As a result, before adopting an IDS, considerable preparation and thought are required. The paper isolates the concerns and concentrates on why IDS and EDS are required for delivering secure network service. Because one of the most important criteria for enabling privacy is security.Loss or 
unauthorized access, deletion, use, alteration, or disclosure of personal data should all be safeguarded by appropriate security precautions. Work on system design and algorithm design for secure communication over complicated networks can be done in the future.

In this paper, we have provided the thorough survey and the state-of-the-art of existing intrusion and extrusion events and introduced a refined security analyses by means of threats, counter measures and future research directions. The comprehensive review presented in our work may provide designers with new means to look for solutions in a unified manner according to several security and resource parameters. Finally, we are aware that attacks other than those considered in this paper might exist. We strongly believe that addressing provable security of intrusion and extrusion events is a challenge for future research, but not impossible.

\section{CONFLICT OF INTEREST}

On behalf of all authors, the corresponding author states that there is no conflict of interest.

\section{REFERENCES}

[1] R. Mahmoud, T. Yousuf, F. Aloul, and I. Zualkernan, "Internet of things (iot) security: Current status, challenges and prospective measures," in 2015 10th International Conference for Internet Technology and Secured Transactions (ICITST). IEEE, 2015, pp. 336-341.

[2] J. Deogirikar and A. Vidhate, "Security attacks in iot: A survey," in 2017 International Conference on I-SMAC (IoT in Social, Mobile, Analytics and Cloud)(I-SMAC). IEEE, 2017, pp. 32-37.

[3] Z.-K. Zhang, M. C. Y. Cho, C.-W. Wang, C.-W. Hsu, C.-K. Chen, and S. Shieh, "Iot security: ongoing challenges and research opportunities," in 2014 IEEE 7th international conference on service-oriented computing and applications. IEEE, 2014, pp. 230-234.

[4] J. Gubbi, R. Buyya, S. Marusic, and M. Palaniswami, "Internet of things (iot): A vision, architectural elements, and future directions," Future generation computer systems, vol. 29, no. 7, pp. 1645-1660, 2013.

[5] K. Zhao and L. Ge, "A survey on the internet of things security," in 2013 Ninth international conference on computational intelligence and security. IEEE, 2013, pp. 663-667.

[6] M. Antonakakis, T. April, M. Bailey, M. Bernhard, E. Bursztein, J. Cochran, Z. Durumeric, J. A. Halderman, L. Invernizzi, M. Kallitsis et al., "Understanding the mirai botnet," in 26th \{USENIX\} Security Symposium (\{USENIX\} Security 17), 2017, pp. 1093-1110.

[7] C. Kolias, G. Kambourakis, A. Stavrou, and J. Voas, "Ddos in the iot: Mirai and other botnets," Computer, vol. 50, no. 7, pp. 80-84, 2017.

[8] M. F. Muhammad, W. Anjum, and K. S. Mazhar, "A critical analysis on the security concerns of internet of things (iot)," International Journal of Computer Applications (0975 8887), vol. 111, no. 7, 2015.

[9] Y. Yang, L. Wu, G. Yin, L. Li, and H. Zhao, "A survey on security and privacy issues in internet-of-things," IEEE Internet of Things Journal, vol. 4, no. 5, pp. 1250-1258, 2017.

[10] O. Said and M. Masud, "Towards internet of things: Survey and future vision," International Journal of Computer Networks, vol. 5, no. 1, pp. $1-17,2013$.

[11] S. Kraijak and P. Tuwanut, "A survey on iot architectures, protocols, applications, security, privacy, real-world implementation and future trends," 2015.

[12] D. Peraković, M. Periša, and I. Cvitić, "Analysis of the iot impact on volume of ddos attacks," XXXIII Simpozijum o novim tehnologijama u poštanskom i telekomunikacionom saobraćaju-PosTel, vol. 2015, pp. 295-304, 2015.

[13] K. Sonar and H. Upadhyay, "A survey: Ddos attack on internet of things," International Journal of Engineering Research and Development, vol. 10, no. 11, pp. 58-63, 2014.
[14] Y. Meidan, M. Bohadana, Y. Mathov, Y. Mirsky, A. Shabtai, D. Breitenbacher, and Y. Elovici, "N-baiot-network-based detection of iot botnet attacks using deep autoencoders," IEEE Pervasive Computing, vol. 17 , no. 3, pp. 12-22, 2018.

[15] T. F. Lunt, "A survey of intrusion detection techniques," Computers and Security, vol. 12, no. 4, pp. 405-418, 1993.

[16] H.-J. Liao, C.-H. R. Lin, Y.-C. Lin, and K.-Y. Tung, "Intrusion detection system: A comprehensive review," Journal of Network and Computer Applications, vol. 36, no. 1, pp. 16-24, 2013.

[17] R. Mitchell and I.-R. Chen, "A survey of intrusion detection techniques for cyber-physical systems," ACM Computing Surveys (CSUR), vol. 46, no. 4, p. 55, 2014.

[18] A. Tuteja and R. Shanker, "Optimization of snort for extrusion and intrusion detection and prevention," International Journal of Engineering Research and Applications, vol. 2, no. 3, pp. 1768-1774, 2012.

[19] M. J. Lekha, G. Padmavathi, and D. C. Wyld, "A comprehensive study on classification of passive intrusion and extrusion detection system," in ICCSEA, SPPR, CSIA, WimoA-2013. Citeseer, 2013, pp. 281-292.

[20] A. Gurina and V. Eliseev, "Anomaly-based method for detecting multiple classes of network attacks," Information, vol. 10, no. 3, p. 84, 2019.

[21] Y. Li, L. Tian, H. Qiu, and C. Zhang, "Distributed shadow for router security defense," International Journal of Software Engineering and Knowledge Engineering, vol. 28, no. 02, pp. 193-206, 2018.

[22] N. Hubballi and J. Santini, "Detecting tcp ack storm attack: a state transition modelling approach," IET Networks, vol. 7, no. 6, pp. 429434, 2018.

[23] T. Duval, B. Jouga, and L. Roger, "The mitnick case: How bayes could have helped," in IFIP International Conference on Digital Forensics. Springer, 2005, pp. 91-104.

[24] O. Sbai and M. Elboukhari, "Classification of mobile ad hoc networks attacks," in 2018 IEEE 5th International Congress on Information Science and Technology (CiSt). IEEE, 2018, pp. 618-624.

[25] R. Abramov and A. Herzberg, "Tcp ack storm dos attacks," in IFIP International Information Security Conference. Springer, 2011, pp. 29-40.

[26] S. N. Duc, M. Mimura, and H. Tanaka, "An analysis of tcp ack storm dos attack on virtual network," in 2019 19th International Symposium on Communications and Information Technologies (ISCIT). IEEE, 2019, pp. 288-293.

[27] I. Topalova, P. Radoyska, and S. Sokolov, "Neural network implementation for detection of denial of service attacks," Journal of Engineering Science and Technology Review, 2019.

[28] S. Acharya and N. Tiwari, "Survey of ddos attacks based on tcp/ip protocol vulnerabilities," IOSR Journal of Computer Engineering, vol. 18 , no. 3, pp. 68-76, 2016.

[29] Y. Chen, "A novel marking-based detection and filtering scheme against distributed denial of service attack," Ph.D. dissertation, University of Ottawa (Canada), 2006.

[30] U. Tariq, M. Hong, and K.-s. Lhee, "A comprehensive categorization of ddos attack and ddos defense techniques," in International Conference on Advanced Data Mining and Applications. Springer, 2006, pp. 1025-1036.

[31] M. Baentsch, L. Baum, G. Molter, S. Rothkugel, and P. Sturm, "Enhancing the web's infrastructure: From caching to replication," IEEE Internet Computing, vol. 1, no. 2, pp. 18-27, 1997.

[32] J. Xia, Z. Cai, G. Hu, and M. Xu, "An active defense solution for arp spoofing in openflow network," Chinese Journal of Electronics, vol. 28, no. 1, pp. 172-178, 2019.

[33] D. Hanna, P. Veeraraghavan, and E. Pardede, "Precast: An efficient crypto-free solution for broadcast-based attacks in ipv4 networks," Electronics, vol. 7, no. 5, p. 65, 2018.

[34] M. Baltatu, A. Lioy, F. Maino, and D. Mazzocchi, "Security issues in control, management and routing protocols," Computer Networks, vol. 34, no. 6, pp. 881-894, 2000.

[35] P. Arote and K. V. Arya, "Detection and prevention against arp poisoning attack using modified icmp and voting," in 2015 International Conference on Computational Intelligence and Networks. IEEE, 2015, pp. 136-141. 
[36] J. Kaur, "Wired lan and wireless lan attack detection using signature based and machine learning tools," in Networking Communication and Data Knowledge Engineering. Springer, 2018, pp. 15-24.

[37] A. K. Al-Ani, M. Anbar, S. Manickam, A. Al-Ani, and Y.-B. Leau, "Preventing denial of service attacks on address resolution in ipv6 link-local network: Ar-match security technique," in Computational Science and Technology. Springer, 2019, pp. 305-314.

[38] E. Viegas, A. Santin, A. Bessani, and N. Neves, "Bigflow: Realtime and reliable anomaly-based intrusion detection for high-speed networks," Future Generation Computer Systems, vol. 93, pp. 473485, 2019.

[39] J. Andre and J. Naab, "Open vswitch configuration for separation of kvm/libvirt vms," Network, vol. 43, 2019.

[40] C. Shannon, D. Moore et al., "Characteristics of fragmented ip traffic on internet links," in Proceedings of the 1st ACM SIGCOMM Workshop on Internet Measurement. ACM, 2001, pp. 83-97.

[41] A. Le, J. Loo, A. Lasebae, M. Aiash, and Y. Luo, "6lowpan: a study on qos security threats and countermeasures using intrusion detection system approach," International Journal of Communication Systems, vol. 25, no. 9, pp. 1189-1212, 2012.

[42] Z. Trabelsi, S. Zeidan, and K. Hayawi, "Denial of firewalling attacks (dof): The case study of the emerging blacknurse attack," IEEE Access, vol. 7, pp. 61 596-61 609, 2019.

[43] A. Al-Ani, M. Anbar, R. Abdullah, and A. K. Al-Ani, "Proposing a new approach for securing dhcpv6 server against rogue dhcpv6 attack in ipv6 network," in International Conference of Reliable Information and Communication Technology. Springer, 2018, pp. 579-587.

[44] R. A. Rahman and B. Shah, "Security analysis of iot protocols: A focus in coap," in 2016 3rd MEC international conference on big data and smart city (ICBDSC). IEEE, 2016, pp. 1-7.

[45] D. J. Bernstein, N. Duif, T. Lange, P. Schwabe, and B.-Y. Yang, "High-speed high-security signatures," in International Workshop on Cryptographic Hardware and Embedded Systems. Springer, 2012, pp. 124-142.

[46] H. Patel and D. Jinwala, "Stf-dm: a sparsely tagged fragmentation with dynamic marking an ip traceback approach." Int. Arab J. Inf. Technol., vol. 15 , no. 4 , pp. 721-728, 2018.

[47] M. Hossain, Y. Karim, and R. Hasan, "Secupan: A security scheme to mitigate fragmentation-based network attacks in 6lowpan," in Proceedings of the Eighth ACM Conference on Data and Application Security and Privacy. ACM, 2018, pp. 307-318.

[48] C. Zhang, G. Hu, G. Chen, A. K. Sangaiah, P. Zhang, X. Yan, and W. Jiang, "Towards a sdn-based integrated architecture for mitigating ip spoofing attack," IEEE Access, vol. 6, pp. 22 764-22 777, 2017.

[49] D. Bakker, "Impact-based optimisation of bgp flowspec rules for ddos attack mitigation," B.S. thesis, University of Twente, 2019.

[50] A. Al-Ani, M. Anbar, S. A. Laghari, and A. K. Al-Ani, "Mechanism to prevent the abuse of ipv6 fragmentation in openflow networks," PloS one, vol. 15, no. 5, p. e0232574, 2020.

[51] A. Gupta, O. J. Pandey, M. Shukla, A. Dadhich, A. Ingle, and V. Ambhore, "Intelligent perpetual echo attack detection on user datagram protocol port 7 using ant colony optimization," in 2014 International Conference on Electronic Systems, Signal Processing and Computing Technologies. IEEE, 2014, pp. 419-424.

[52] K. Ghirardello, C. Maple, D. Ng, and P. Kearney, "Cyber security of smart homes: Development of a reference architecture for attack surface analysis," 2018.

[53] A. Gupta, O. J. Pandey, M. Shukla, A. Dadhich, A. Ingle, and V. Ambhore, "Intelligent perpetual echo attack detection on user datagram protocol port 7 using ant colony optimization," in 2014 International Conference on Electronic Systems, Signal Processing and Computing Technologies. IEEE, 2014, pp. 419-424.

[54] M. Okeke and A. Blyth, "Adopting flocks of birds approach to predator for anomalies detection on industrial control systems," International Journal of Mathematical, Computational, Physics, Electrical and Computer Engineering, Paris, vol. 10, no. 2016, 2016.

[55] D. Kundur and K. Ahsan, "Practical internet steganography: data hiding in ip," Proc. Texas wksp. security of information systems, 2003.

[56] L. Jacquin, V. Roca, and J.-L. Roch, "Icmp: an attack vector against ipsec gateways," 2013.
[57] M. Myint Oo, S. Kamolphiwong, T. Kamolphiwong, and S. Vasupongayya, "Advanced support vector machine-(asvm-) based detection for distributed denial of service (ddos) attack on software defined networking (sdn)," Journal of Computer Networks and Communications, vol. 2019, 2019.

[58] S. Kumar, "Smurf-based distributed denial of service (ddos) attack amplification in internet," in Second International Conference on Internet Monitoring and Protection (ICIMP 2007). IEEE, 2007, pp. $25-25$.

[59] J. Agarkhed, G. Kalnoor, and S. R. Patil, "Intrusion detection system using pattern matching techniques for wireless sensor networks," in Innovations in Computer Science and Engineering. Springer, 2019, pp. $411-418$.

[60] T. V. Phan and M. Park, "Efficient distributed denial-of-service attack defense in sdn-based cloud," IEEE Access, vol. 7, pp. 18701-18 714, 2019.

[61] A. K. Biswas, S. Nandy, and R. Narayan, "Router attack toward nocenabled mpsoc and monitoring countermeasures against such threat," Circuits, Systems, and Signal Processing, vol. 34, no. 10, pp. 32413290, 2015

[62] A. R. B. Patil and N. V. Thakur, "Mitigation against denial-ofservice flooding and malformed packet attacks," in Third International Congress on Information and Communication Technology. Springer, 2019, pp. 335-342.

[63] M. Bykova, S. Ostermann, and B. Tjaden, "Detecting network intrusions via a statistical analysis of network packet characteristics," in Proceedings of the 33rd Southeastern Symposium on System Theory (Cat. No. 01EX460). IEEE, 2001, pp. 309-314.

[64] N. Security, "Protecting our routers," https://www.nanolocksecurity.c om/protecting-our-routers-why-a-password-change-or-software-upda te-is-just-not-enough// 2020.

[65] R. Shinohara, T. Kamimoto, K. Sato, and H. Shigeno, "Cache control method mitigating packet concentration of router caused by interest flooding attack," in 2016 IEEE Trustcom/BigDataSE/ISPA. IEEE, 2016, pp. 324-331.

[66] L. Daoud and N. Rafla, "Detection and prevention protocol for black hole attack in network-on-chip," in Proceedings of the 13th IEEE/ACM International Symposium on Networks-on-Chip, 2019, pp. 1-2.

[67] S. Specht and R. Lee, "Taxonomies of distributed denial of service networks, attacks, tools and countermeasures," Technical Report CEL2003-03, 2003.

[68] M. Ring, D. Landes, and A. Hotho, "Detection of slow port scans in flow-based network traffic," PloS one, vol. 13, no. 9, p. e0204507, 2018.

[69] G. Conti and K. Abdullah, "Passive visual fingerprinting of network attack tools," in Proceedings of the 2004 ACM workshop on Visualization and data mining for computer security. ACM, 2004, pp. 45-54.

[70] M. Dabbagh, A. J. Ghandour, K. Fawaz, W. El Hajj, and H. Hajj, "Slow port scanning detection," in 2011 7th International Conference on Information Assurance and Security (IAS). IEEE, 2011, pp. 228233.

[71] M. Da Silva, M.-L. Flottes, G. Di Natale, and B. Rouzeyre, "Preventing scan attacks on secure circuits through scan chain encryption," IEEE Transactions on Computer-Aided Design of Integrated Circuits and Systems, vol. 38, no. 3, pp. 538-550, 2018.

[72] M. López-Vizcaíno, F. J. Novoa, D. Fernández, V. Carneiro, and F. Cacheda, "Early intrusion detection for os scan attacks," in 2019 IEEE 18th International Symposium on Network Computing and Applications (NCA). IEEE, 2019, pp. 1-5.

[73] M. Almseidin, M. Al-Kasassbeh, and S. Kovacs, "Detecting slow port scan using fuzzy rule interpolation," in 2019 2nd International Conference on new Trends in Computing Sciences (ICTCS). IEEE, 2019, pp. 1-6.

[74] B. Hartpence and A. Kwasinski, "Combating tep port scan attacks using sequential neural networks," in 2020 International Conference on Computing, Networking and Communications (ICNC). IEEE, 2020, pp. 256-260.

[75] G. F. Scaranti, L. F. Carvalho, S. Barbon, and M. L. Proença, "Artificial 
immune systems and fuzzy logic to detect flooding attacks in softwaredefined networks," IEEE Access, 2020.

[76] R. Ritchey, B. O'Berry, and S. Noel, "Representing tcp/ip connectivity for topological analysis of network security," in 18th Annual Computer Security Applications Conference, 2002. Proceedings. IEEE, 2002, pp. 25-31.

[77] M. Kaushik and G. Ojha, "Attack penetration system for sql injection," International journal of advanced computer research, vol. 4, no. 2, p. 724, 2014.

[78] A. Sumalee and F. Kurauchi, "Network capacity reliability analysis considering traffic regulation after a major disaster," Networks and Spatial Economics, vol. 6, no. 3-4, pp. 205-219, 2006.

[79] M. Dubinsky, "The good and bad of 3 common ip white listing scenarios," https://symantec-enterprise-blogs.security.com/blogs/exp ert-perspectives/good-and-bad-3-common-ip-whitelisting-scenarios 2020.

[80] Y. Kim, S. Ahn, N. C. Thang, D. Choi, and M. Park, "Arp poisoning attack detection based on arp update state in software-defined networks," in 2019 International Conference on Information Networking (ICOIN). IEEE, 2019, pp. 366-371.

[81] Z. Trabelsi and K. Shuaib, "Spoofed arp packets detection in switched lan networks," in International Conference on E-Business and Telecommunication Networks. Springer, 2006, pp. 81-91.

[82] D. Adamitis, "Sea turtle keeps on swimming, finds new victims, dns hijacking techniques," https://blog.talosintelligence.com/2019/07/sea-t urtle-keeps-on-swimming.html 2019.

[83] G. Al Sukkar, R. Saifan, S. Khwaldeh, M. Maqableh, and I. Jafar, "Address resolution protocol (arp): spoofing attack and proposed defense," 2016.

[84] S. Singh, D. Singh, and A. M. Tripathi, "Two-phase validation scheme for detection and prevention of arp cache poisoning," in Progress in Advanced Computing and Intelligent Engineering. Springer, 2019, pp. 303-315.

[85] T. Sanguankotchakorn and S. K. Arugonda, "Hybrid controller for securing sdn from switched ddos and arp poisoning attacks," in 2019 20th Asia-Pacific Network Operations and Management Symposium (APNOMS). IEEE, 2019, pp. 1-6.

[86] A. M. Amin and M. S. Mahamud, "An alternative approach of mitigating arp based man-in-the-middle attack using client site bash script," in 2019 6th International Conference on Electrical and Electronics Engineering (ICEEE). IEEE, 2019, pp. 112-115.

[87] A. K. Al-Ani, M. Anbar, A. Al-Ani, and D. R. Ibrahim, "Matchprevention technique against denial-of-service attack on address resolution and duplicate address detection processes in ipv6 link-local network," IEEE Access, vol. 8, pp. 27 122-27 138, 2020.

[88] B. Harris and R. Hunt, "Tcp/ip security threats and attack methods," Computer communications, vol. 22, no. 10, pp. 885-897, 1999.

[89] R. Chirgwin, "Firewalls snuffed by 'blacknurse' ping of death attack," https://www.theregister.com/2016/11/14/its_2016_and_a_ping_of_dea th_can_still_be_a_thing/ 2016.

[90] S. J. Templeton and K. Levitt, "A requires/provides model for computer attacks," in Proceedings of the 2000 workshop on New security paradigms. ACM, 2001, pp. 31-38.

[91] K. Hussain, S. J. Hussain, V. Dillshad, M. Nafees, and M. A. Azeem, "An adaptive syn flooding attack mitigation in ddos environment," International Journal of Computer Science and Network Security (IJCSNS), vol. 16, no. 7, p. 27, 2016.

[92] D. Kshirsagar, S. Sawant, A. Rathod, and S. Wathore, "Cpu load analysis and minimization for tcp syn flood detection," Procedia Computer Science, vol. 85, pp. 626-633, 2016.

[93] P. Kumar, M. Tripathi, A. Nehra, M. Conti, and C. Lal, "Safety: Early detection and mitigation of tcp syn flood utilizing entropy in sdn," IEEE Transactions on Network and Service Management, vol. 15, no. 4, pp. 1545-1559, 2018.

[94] Y. Bae, I. Kim, and S. O. Hwang, "An efficient detection of tcp syn flood attacks with spoofed ip addresses," Journal of Intelligent and Fuzzy Systems, vol. 35, no. 6, pp. 5983-5991, 2018.

[95] X. Zhong and Y. Liu, "Detection and defense of syn flood attack based on winpcap," in International Conference on Mechatronics and Intelligent Robotics. Springer, 2018, pp. 249-257.
[96] K. Hussain, S. J. Hussain, N. Jhanjhi, and M. Humayun, "Syn flood attack detection based on bayes estimator (sfadbe) for manet," in 2019 International Conference on Computer and Information Sciences (ICCIS). IEEE, 2019, pp. 1-4.

[97] V. T. Dang, T. T. Huong, N. H. Thanh, P. N. Nam, N. N. Thanh, and A. Marshall, "Sdn-based syn proxy-a solution to enhance performance of attack mitigation under tcp syn flood," The Computer Journal, vol. 62, no. 4, pp. 518-534, 2019.

[98] S. Evmorfos, G. Vlachodimitropoulos, N. Bakalos, and E. Gelenbe, "Neural network architectures for the detection of syn flood attacks in iot systems," in Proceedings of the 13th ACM International Conference on PErvasive Technologies Related to Assistive Environments, 2020, pp. $1-4$.

[99] R. R. Kompella, S. Singh, and G. Varghese, "On scalable attack detection in the network," in Proceedings of the 4th ACM SIGCOMM conference on Internet measurement. ACM, 2004, pp. 187-200.

[100] J. Haggerty, T. Berry, Q. Shi, and M. Merabti, "Diddem: a system for early detection of tcp syn flood attacks," in IEEE Global Telecommunications Conference, 2004. GLOBECOM'04., vol. 4. IEEE, 2004, pp. 2037-2042.

[101] M. Bogdanoski, T. Suminoski, and A. Risteski, "Analysis of the syn flood dos attack," International Journal of Computer Network and Information Security (IJCNIS), vol. 5, no. 8, pp. 1-11, 2013.

[102] P. Nicholson, "Five most famous ddos attacks and then some," https: //www.a10networks.com/blog/5-most-famous-ddos-attacks/ 2020.

[103] M. Masdari and M. Jalali, "A survey and taxonomy of dos attacks in cloud computing," Security and Communication Networks, vol. 9, no. 16 , pp. 3724-3751, 2016.

[104] G. Carl, G. Kesidis, R. R. Brooks, and S. Rai, "Denial-of-service attack-detection techniques," IEEE Internet computing, vol. 10, no. 1, pp. 82-89, 2006.

[105] Z. Yu, L. Yang, and T. Fu, "Network attack defense policy sending method and apparatus, and network attack defending method and apparatus," Nov. 22 2018, uS Patent App. 16/050,313.

[106] S. B. Venugopal and S. B. Venugopal, "Automatic generation of access control list on mellanox switch for ddos attack mitigation using ddos fingerprints," Master's thesis, University of Twente, 2019.

[107] D. L. Ponemon, "Opus and ponemon institute announce results of 2018," https://www.businesswire.com/news/home/20181115005665/ en/Opus-Ponemon-Institute-Announce-Results-of-2018-Third-Party -Data-Risk-Study-59-of-Companies-Experienced-a-Third-Party-Dat a-Breach-Yet-Only-16-Say-They-Effectively-Mitigate-Third-Party-R isks 2018.

[108] S. Kumar, "Impact of distributed denial of service (ddos) attack due to arp storm," in International Conference on Networking. Springer, 2005, pp. 997-1002.

[109] A. Saied, R. E. Overill, and T. Radzik, "Detection of known and unknown ddos attacks using artificial neural networks," Neurocomputing, vol. 172, pp. 385-393, 2016.

[110] Z. Liu, Y. Cao, M. Zhu, and W. Ge, "Umbrella: Enabling isps to offer readily deployable and privacy-preserving ddos prevention services," IEEE Transactions on Information Forensics and Security, vol. 14, no. 4, pp. 1098-1108, 2018.

[111] S. Y. Mehr and B. Ramamurthy, "An svm based ddos attack detection method for ryu sdn controller," in Proceedings of the 15th International Conference on emerging Networking EXperiments and Technologies, 2019, pp. 72-73.

[112] J. David and C. Thomas, "Efficient ddos flood attack detection using dynamic thresholding on flow-based network traffic," Computers and Security, vol. 82, pp. 284-295, 2019.

[113] R. Saxena and S. Dey, "Ddos attack prevention using collaborative approach for cloud computing," Cluster Computing, pp. 1-16, 2019.

[114] M. Wang, Y. Lu, and J. Qin, "A dynamic mlp-based ddos attack detection method using feature selection and feedback," Computers and Security, vol. 88, p. 101645, 2020.

[115] D. Shree, "A review on cryptography, attacks and cyber security," International Journal of Advanced Research in Computer Science, vol. 8, no. 5, 2017.

[116] J. A. Chaudhry, S. A. Chaudhry, and R. G. Rittenhouse, "Phishing 
attacks and defenses," International Journal of Security and Its Applications, vol. 10, no. 1, pp. 247-256, 2016.

[117] D. S. Berman, A. L. Buczak, J. S. Chavis, and C. L. Corbett, "A survey of deep learning methods for cyber security," Information, vol. 10, no. 4, p. 122, 2019.

[118] A. K. Jain and B. Gupta, "Phish-safe: Url features-based phishing detection system using machine learning," in Cyber Security. Springer, 2018, pp. 467-474.

[119] M. A. Adebowale, K. T. Lwin, E. Sanchez, and M. A. Hossain, "Intelligent web-phishing detection and protection scheme using integrated features of images, frames and text," Expert Systems with Applications, vol. 115, pp. 300-313, 2019.

[120] R. S. Rao and A. R. Pais, "Jail-phish: An improved search engine based phishing detection system," Computers and Security, vol. 83, pp. 246-267, 2019.

[121] M. T. Suleman and S. M. Awan, "Optimization of url-based phishing websites detection through genetic algorithms," Automatic Control and Computer Sciences, vol. 53, no. 4, pp. 333-341, 2019.

[122] S. W. Liew, N. F. M. Sani, M. T. Abdullah, R. Yaakob, and M. Y. Sharum, "An effective security alert mechanism for real-time phishing tweet detection on twitter," Computers and Security, vol. 83, pp. 201207, 2019.

[123] J. Mao, J. Bian, W. Tian, S. Zhu, T. Wei, A. Li, and Z. Liang, "Phishing page detection via learning classifiers from page layout feature," EURASIP Journal on Wireless Communications and Networking, vol. 2019, no. 1, p. 43, 2019.

[124] A. K. Jain and B. B. Gupta, "A machine learning based approach for phishing detection using hyperlinks information," Journal of Ambient Intelligence and Humanized Computing, vol. 10, no. 5, pp. 2015-2028, 2019.

[125] K. L. Chiew, C. L. Tan, K. Wong, K. S. Yong, and W. K. Tiong, "A new hybrid ensemble feature selection framework for machine learningbased phishing detection system," Information Sciences, vol. 484, pp. 153-166, 2019.

[126] A. Orunsolu, A. Sodiya, and A. Akinwale, "A predictive model for phishing detection," Journal of King Saud University-Computer and Information Sciences, 2019.

[127] H. Y. Lam, R. E. Ashley, P. T. Mathison, Q. Li, and T. Ettema, "Outbound/inbound lateral traffic punting based on process risk," Mar. 21 2019, uS Patent App. 15/705,516.

[128] E. Mulyana and U. Killat, "Optimizing ip networks for uncertain demands using outbound traffic constraints," in Proceedings of INOC, vol. 2005. Citeseer, 2005.

[129] Y. Zhou and X. Jiang, "Dissecting android malware: Characterization and evolution," in 2012 IEEE symposium on security and privacy. IEEE, 2012, pp. 95-109.

[130] C.-S. Chang, "On deterministic traffic regulation and service guarantees: a systematic approach by filtering," IEEE Transactions on Information Theory, vol. 44, no. 3, pp. 1097-1110, 1998.

[131] Y. Sawa, R. Bhakta, I. G. Harris, and C. Hadnagy, "Detection of social engineering attacks through natural language processing of conversations," in 2016 IEEE Tenth International Conference on Semantic Computing (ICSC). IEEE, 2016, pp. 262-265.

[132] K. Y. Abeywardana, E. Pfluegel, and M. J. Tunnicliffe, "A layered defense mechanism for a social engineering aware perimeter," in 2016 SAI Computing Conference (SAI). IEEE, 2016, pp. 1054-1062.

[133] A. Dan and S. Gupta, "Social engineering attack detection and data protection model (seaddpm)," in Proceedings of International Ethical Hacking Conference 2018. Springer, 2019, pp. 15-24.

[134] M. Lansley, N. Polatidis, S. Kapetanakis, K. Amin, G. Samakovitis, and M. Petridis, "Seen the villains: Detecting social engineering attacks using case-based reasoning and deep learning," in Workshops Proceedings for the Twenty-seventh International Conference on CaseBased Reasoning: Case-based reasoning and deep learning workshop, 2019.

[135] F. Mouton, A. Nottingham, L. Leenen, and H. Venter, "Finite state machine for the social engineering attack detection model: Seadm," SAIEE Africa Research Journal, vol. 109, no. 2, pp. 133-148, 2018.

[136] F. Mouton, M. M. Malan, L. Leenen, and H. S. Venter, "Social engineering attack framework," in 2014 Information Security for South Africa. IEEE, 2014, pp. 1-9.

[137] K. Krombholz, H. Hobel, M. Huber, and E. Weippl, "Advanced social engineering attacks," Journal of Information Security and applications, vol. 22, pp. 113-122, 2015.

[138] R. Heartfield and G. Loukas, "A taxonomy of attacks and a survey of defence mechanisms for semantic social engineering attacks," ACM Computing Surveys (CSUR), vol. 48, no. 3, p. 37, 2016.

[139] S. K. Sahay, A. Sharma, and H. Rathore, "Evolution of malware and its detection techniques," in Information and Communication Technology for Sustainable Development. Springer, 2020, pp. 139-150.

[140] I. Burguera, U. Zurutuza, and S. Nadjm-Tehrani, "Crowdroid: behavior-based malware detection system for android," in Proceedings of the 1st ACM workshop on Security and privacy in smartphones and mobile devices. ACM, 2011, pp. 15-26.

[141] A. Saracino, D. Sgandurra, G. Dini, and F. Martinelli, "Madam: Effective and efficient behavior-based android malware detection and prevention," IEEE Transactions on Dependable and Secure Computing, vol. 15, no. 1, pp. 83-97, 2016.

[142] A. Dinaburg, P. Royal, M. Sharif, and W. Lee, "Ether: malware analysis via hardware virtualization extensions," in Proceedings of the 15th ACM conference on Computer and communications security. ACM, 2008, pp. 51-62.

[143] A. Moser, C. Kruegel, and E. Kirda, "Limits of static analysis for malware detection," in Twenty-Third Annual Computer Security Applications Conference (ACSAC 2007). IEEE, 2007, pp. 421-430.

[144] P. Mishra, K. Khurana, S. Gupta, and M. K. Sharma, "Vmanalyzer: Malware semantic analysis using integrated $\mathrm{cnn}$ and bi-directional lstm for detecting vm-level attacks in cloud," in 2019 Twelfth International Conference on Contemporary Computing (IC3). IEEE, 2019, pp. 1-6.

[145] D. Maiorca, B. Biggio, and G. Giacinto, "Towards adversarial malware detection: Lessons learned from pdf-based attacks," ACM Computing Surveys (CSUR), vol. 52, no. 4, pp. 1-36, 2019.

[146] C. Gan, Q. Feng, X. Zhang, Z. Zhang, and Q. Zhu, "Dynamical propagation model of malware for cloud computing security," IEEE Access, 2020.

[147] M. Alazab, M. Alazab, A. Shalaginov, A. Mesleh, and A. Awajan, "Intelligent mobile malware detection using permission requests and api calls," Future Generation Computer Systems, 2020.

[148] P. Mishra, I. Verma, and S. Gupta, "Kvminspector: Kvm based introspection approach to detect malware in cloud environment," Journal of Information Security and Applications, vol. 51, p. 102460, 2020.

[149] G. Gu, J. Zhang, and W. Lee, "Botsniffer: Detecting botnet command and control channels in network traffic," 2008.

[150] A. Karasaridis, B. Rexroad, D. A. Hoeflin et al., "Wide-scale botnet detection and characterization." HotBots, vol. 7, pp. 7-7, 2007.

[151] S. Amina, R. Vera, T. Dargahi, and A. Dehghantanha, "A bibliometric analysis of botnet detection techniques," in Handbook of Big Data and IoT Security. Springer, 2019, pp. 345-365.

[152] A. Praseed and P. S. Thilagam, "Ddos attacks at the application layer: Challenges and research perspectives for safeguarding web applications," IEEE Communications Surveys and Tutorials, vol. 21, no. 1, pp. 661-685, 2018.

[153] J. M. Ceron, K. Steding-Jessen, C. Hoepers, L. Z. Granville, and C. B. Margi, "Improving iot botnet investigation using an adaptive network layer," Sensors, vol. 19, no. 3, p. 727, 2019.

[154] R. Swami, M. Dave, and V. Ranga, "Software-defined networkingbased ddos defense mechanisms," ACM Computing Surveys (CSUR), vol. 52 , no. 2, p. $28,2019$.

[155] C. Tzagkarakis, N. Petroulakis, and S. Ioannidis, "Botnet attack detection at the iot edge based on sparse representation," in 2019 Global IoT Summit (GIoTS). IEEE, 2019, pp. 1-6.

[156] M. Banerjee and S. Samantaray, "Network traffic analysis based iot botnet detection using honeynet data applying classification techniques," International Journal of Computer Science and Information Security (IJCSIS), vol. 17, no. 8, 2019.

[157] S. Dange and M. Chatterjee, "Iot botnet: The largest threat to the iot network," in Data Communication and Networks. Springer, 2020, pp. $137-157$. 